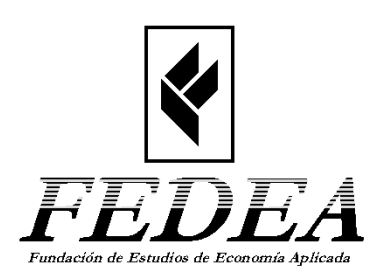

\author{
Protecting Against Labour Market Risk: Employment \\ Protection or Unemployment Benefits? \\ by \\ Tito Boeri* \\ J. Ignacio Conde-Ruiz** \\ Vincenzo Galasso $* * *$ \\ DOCUMENTO DE TRABAJO 2003-17
}

July 2003

* Università Bocconi, IGIER, and Fondazione Rodolfo Debenedetti.

** FEDEA.

** IGIER, Università Bocconi and CEPR.

Los Documentos de Trabajo se distribuyen gratuitamente a las Universidades e Instituciones de Investigación que lo solicitan. No obstante están disponibles en texto completo a través de Internet: http://www.fedea.es/hojas/publicaciones.html\#Documentos de Trabajo

These Working Documents are distributed free of charge to University Department and other Research Centres. They are also available through Internet: http://www.fedea.es/hojas/publicaciones.html\#Documentos de Trabajo 


\title{
Protecting Against Labour Market Risk: Employment Protection or Unemployment Benefits?
}

\author{
Tito Boeri* \\ Università Bocconi, IGIER, and Fondazione Rodolfo Debenedetti \\ J. Ignacio Conde-Ruiz \\ Vincenzo Galasso \\ FEDEA \\ IGIER, Università Bocconi and CEPR
}

June 2003

${ }^{*}$ Tito Boeri, Università Bocconi, IGIER and Fondazione Rodolfo Debenedetti, via Salasco 3-5, Milano, 20136, tito.boeri@uni-bocconi.it. Jose Ignacio Conde-Ruiz, FEDEA, C/Jorge Juan 46, Madrid, 28001, conde-ruiz@fedea.es, Vincenzo Galasso, IGIER, Università Bocconi, via salasco 5, 20136, Milano, vincenzo.galasso@uni-bocconi.it. We thank Alberto Alesina, Lars Calmfors, Pietro Garibaldi, Gerd Muehlheusser, Torsten Persson, Barbara Petrongolo, Kjetil Storesletten, Guido Tabellini and participants at the fRDB/CEPR conference on "Non-standard labor contracts" for useful comments. Conde-Ruiz and Galasso acknowledge financial support from the Spanish Minister of Science and Technology, project SEC-2002-03421. All remaining errors are ours. 


\begin{abstract}
We document the presence of a trade-off between unemployment benefits (UB) and employment protection legislation (EPL) in the provision of insurance against labour market risk. The mix of quantity restrictions and price regulations adopted by the various countries would seem to correspond to a stable politico-economic equilibrium. We develop a model in which voters are required to cast a ballot over the strictness of EPL and over the generosity of UB. Agents are heterogeneous along two dimensions: employment status - there are insiders and outsiders - and skills - low and high skills. We show that if there exists a majority of low-skill insiders, the voting game has a politico-economic equilibrium with low UB and high EPL; otherwise, the equilibrium features high UB and low EPL. Another testable implication of the model is that a larger share of elderly workers increases the demand for EPL. Panel data on institutions and on the age and educational structures of the populations are broadly in line with our results. We also find that those favouring EPL over UB in a public opinion poll carried in 2001 in Italy have precisely the same characteristics predicted by our model.

Keywords: employment protection, unemployment insurance, political equilibria.

JEL Classification: J68, J65, D72.
\end{abstract}




\section{Introduction}

Unemployment benefits (UBs) and firing costs or, more broadly, employment protective legislation (EPL) are two ways of protecting individuals against the risks of being unemployed. While EPL protects those who already have a job, and does not impose any explicit tax burden, UBs generally provide insurance to a larger portion of the labour force and are financed by a tax imposed on labour income. European countries use different combinations of the two institutions. Plotted against each other, various measures of the two institutions point to the presence of a trade-off between EPL and UBs: those countries, which adopt stronger dismissal restrictions, tend to enjoy smaller unemployment insurance programs, and viceversa.

These different policy mixes would seem to correspond to stable politico-economic equilibria. Stronger competitive pressures, as those arising in the context of so-called "globalization" and EMU-driven price transparency, shift the balance of the two institutions in favour of mobility-friendly unemployment benefits. Job-security oriented labour market institutions, which are focused on protection of primary breadwinners' labour income, are indeed ill-suited to accommodate new demands for mobility and, more broadly, microeconomic adjustment (Boeri and Bertola, 2003). However, moving along this trade-off is proving very difficult. Reforms of EPL are generally confined to introducing "at the margin" more flexible contractual types, rather than modifying rules for workers who already have a permanent contract.

Why do countries resort to different combinations of employment protection and unemployment insurance to protect the individuals against the risk of being unemployed? Why is proving so difficult to move away from these institutional configurations? This paper provides a politico-economic explanation of the observed trade-off between EPL and UBs, applying for the first time (to our knowledge) a multidimensional voting approach to endogenous labour market institutions theory. Our model bridges the gap between two streams of literature in the political economy of labour markets. On the one hand, our environment is similar to that proposed by Wright (1986) to examine the unemployment insurance program. On the other hand, it draws on Saint-Paul (1996) in modeling choices over EPL.

The focus is on the conflict of interest between employed (insiders) and unemployed (outsiders). The transition between these two states - employment and unemployment - is regulated by the unemployment inflow and outflow rates, which are affected by the degree of EPL. The model is further enriched by introducing a second degree of heterogeneity, and thus an additional conflict of interest. As in Acemoglu et al. (2000), workers differ in their skill level. In our model, skills affect the productivity of the agents and the unemployment inflow and outflow rates. In absence of restrictions, high skill types would earn higher wages and face respectively a lower unemployment inflow rate, due mainly to a higher job-to-job mobility, and a higher outflow rate than the low 
types.

In our political economy model, voters are required to cast a ballot over the strictness of EPL and over the generosity of unemployment benefits. Because of the multidimensionality of the issue space, the existence of a Condorcet winner of the majority voting game is not guaranteed. To overcome this problem, we concentrate on political equilibria induced by institutional restrictions, or structure-induced equilibria (see Shepsle,1979 and Persson and Tabellini, 2000). In our political system, the entire electorate votes over the two issues (i.e., the payroll tax financing unemployment benefits and the strictness of employment protection), and policy decisions are taken issue-by-issue.

We show that if the low-skill insiders constitute a majority of the population, the voting game has a politico-economic steady state equilibrium with positive, yet low, unemployment benefits and a high degree of EPL. If, on the other hand, there are enough high skill types (either employed or unemployed) and low-skill outsiders, the politico-economic equilibrium displays a high level of unemployment benefits and a relatively low degree of EPL. Hence, a trade-off between UB and EPL may emerge, depending on the skill structure of the population. The intuition is as follows. For sensible specifications of the parameters, low-skill insiders are always pivotal in deciding over the unemployment insurance, whereas the pivotal voter over the degree of EPL depends on the skill structure of the economy. If the low skill insiders are a majority, they will choose to protect their job with a high degree of EPL, and hence they will demand low employment insurance. If low skill insiders are not a majority, the pivotal group - the low skill outsiders - will choose a lower degree of EPL and hence the low skill insiders will demand more employment insurance. Moreover, our model suggests that a trade off may arise even in a country with a majority of low skill insiders, depending on the age structure of the working population. In fact, a larger share of elderly workers increases the demand for EPL, while reducing the demand for UB.

Panel data on institutions and on the age and educational structures of the populations are broadly in line with the implications of our model. We also find that those favouring EPL over UB in a public opinion poll carried in 2001 in Italy have precisely the same characteristics predicted by theory.

The paper proceeds as follows: Section 2 documents the trade-off and reviews the related literature, Section 3 presents the model and the economic environment. Section 4 develops the political system, and introduces the equilibrium concept. In section 5 , we bring the model's main assumptions and its results to the data. Sections 6 concludes.

\section{The trade-off}

Figure 2.1 documents the aggregate trade-off between UB and EPL in a sample of European countries. It displays, on the vertical axis, an index of the strictness of employment protection compiled by the OECD (OECD, 1999) on the basis of an assessment 


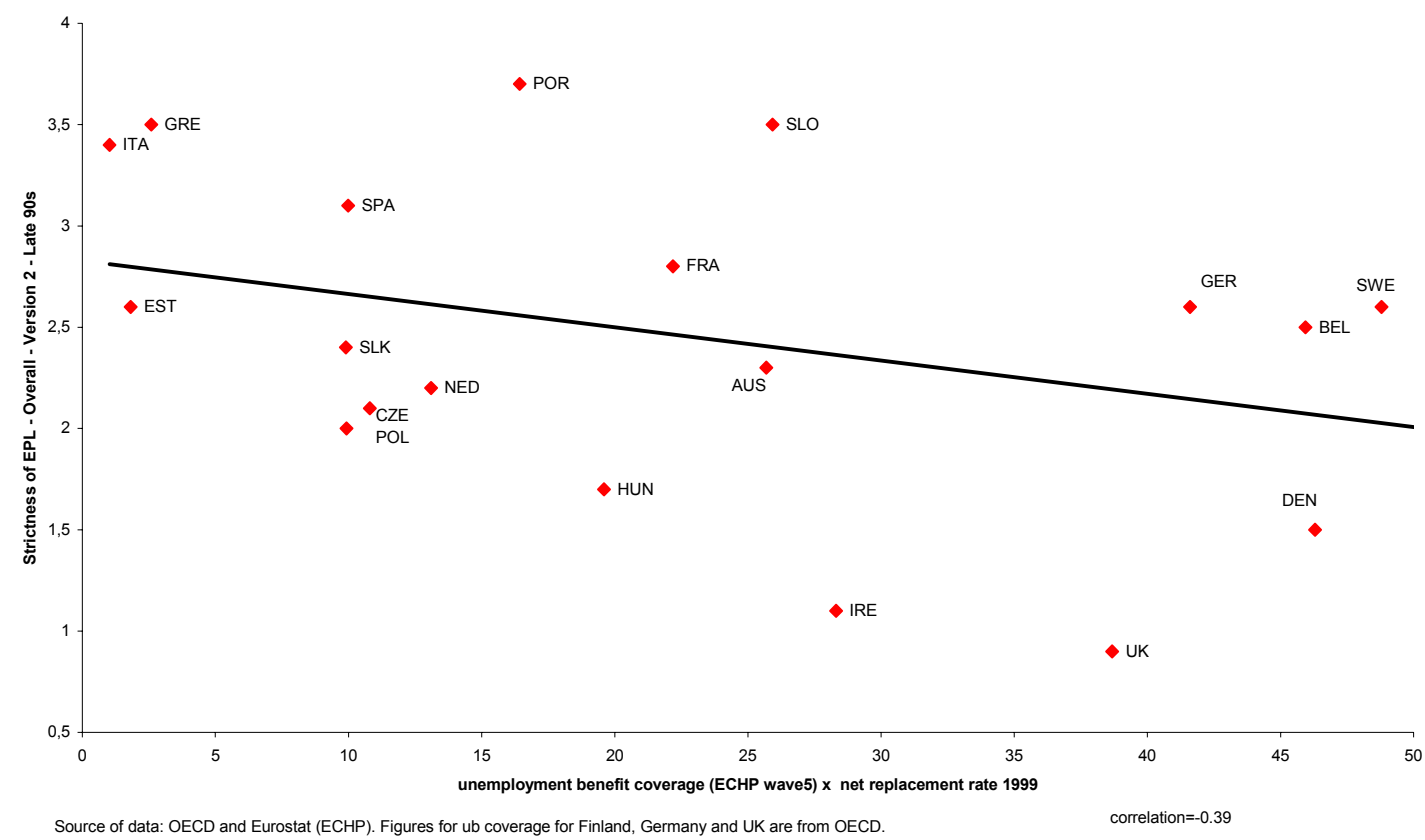

Figure 2.1: The trade-off

of national legislations. The horizontal axis indicates the coverage of unemployment insurance and unemployment assistance (the fraction of unemployed receiving some form of UBs) times the net replacement rate (unemployment benefits in the first year of unemployment as a fraction of the previous wage, both net of taxes). Coverage rates are estimated on the basis of the European Community Household Panel (ECHP) for the EU-15 and from administrative sources in the case of EU candidate countries. The charts hints at a negative relation between the two schemes: the correlation coefficient is -.39 and is significant at 99 per cent. The Southern European countries, in particular, exhibit comparatively high costs of dismissals and a low coverage of UBs.

A low coverage of UBs may also be associated with high youth unemployment rates - which tend to be positively correlated with EPL - as first-time job-seekers typically do not qualify for UBs. However, the negative correlation between UB and EPL is stronger when concentrating on central age groups, whose unemployment rate was found, in many cross-sectional studies (e.g., see OECD, 1999), to be uncorrelated with EPL. This negative correlation holds also when choosing alternative measures of UB generosity, 
such as net replacement rates in the first-year of unemployment insurance, which do not suffer from this potential endogeneity problem and when concentrating on central age groups. Table 1 displays the correlations of EPL with UB coverage and net replacement rates in the first 12 months of unemployment ${ }^{1}$ as well as the product between replacement rates and coverage for the ECHP countries. The coefficients are tabulated for the entire population in working age and for the male prime age group (25 to 45).

Table 1 Alternative measures of the trade-off (late 1990s)

$\begin{array}{lll}\text { EPL correlated with } & \text { Working-age population } & \text { Male prime-age (25 to 45) } \\ \text { a. UB coverage } & -.63^{* *} & -.71^{* *} \\ \text { b. UB net replacement rate } & -.34^{*} & - \\ a^{*} b & -.55^{* *} & -.66^{* *} \\ * * \text { significant at } 99 & * \text { significant at } 95 & \text { nr of observations }=14\end{array}$

The trade-off can also be detected when confining to formerly planned economies: Hungary, for instance, has more generous UBs and less strict EPL than Poland, Czech and Slovak Republics or Estonia. The cross-country variation in the EPL-UB generosity mix is significant in this group of countries. This is important as EU candidate countries had to introduce UBs from scratch (Boeri, 2000) and reform their Labour Codes as unemployment was legally forbidden under central planning. In other words, they could freely choose where to locate along this trade-off. This suggests that the UB-EPL tradeoff cannot be traced to legacies of the past, such as the poorer welfare states of Southern Europe compared with the richer Nordics. Former planned economies, starting from similar conditions and facing broadly the same challenges in the transition to a market economy, resorted to alternative combinations of the two institutional features.

The trade-off has also been documented at the micro level. In particular, Boeri, Boersch-Supan and Tabellini (1999) found that individuals, who consider themselves to be protected by EPL, are less willing to purchase state-provided unemployment insurance and their willingness to pay for UBs is lower than for individuals with a high subjective risk of job loss.

Economic theory, notably the literature on labour market institutions, provides a rationale for the substitutability between EPL and UB. They both protect workers against labour market risk. Models assigning a welfare-enhancing role to these institutions (e.g., Pissarides, 2001) show that - when severance payments and notice periods in case of dismissals are chosen optimally - there is no role for unemployment insurance. The two institutions may also have important design features in common. For instance, when EPL involves only transfers from the employer to the employee (i.e., it is a severance cum notice period scheme), it may collapse to an experience-rated unemployment

\footnotetext{
${ }^{1}$ Buti, Pench and Sestito (1998) also looked at the pairwise correlation between UB replacement rates and EPL strictness.
} 


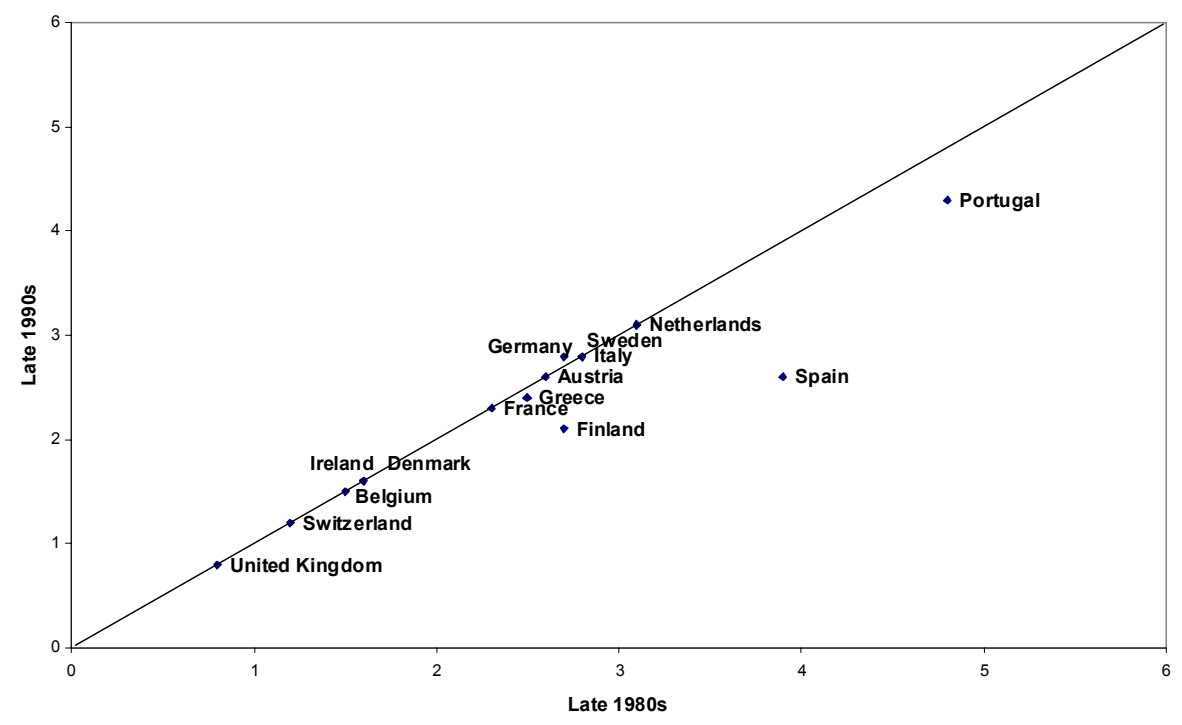

Figure 2.2: EPL for regular workers: late 1990s vs. late 1980s

insurance scheme. However, job security provisions, in addition to payments from the employer to departing employees, typically involve judicial or administrative costs that are deadweight from the point of view of the individual employment relationship.

Interestingly, the presence of a trade-off between UBs and EPL is implicitly acknowledged by the EU Broad Economic Guidelines which state that Member States should "review employment contract regulations and, where appropriate, related costs, with the aim of promoting a proper balance between flexibility and security". Southern European countries have been repeatedly recommended to "reform employment protection legislation" or to "make work contracts more flexible". These policy recommendations draw on second-best arguments in favour of combinations substituting EPL with UBs, e.g., moving towards the South-East of Figure 2.1. Both UB and EPL trade-off lower productive efficiency against ex ante distributional equity. In presence of stronger competitive pressures, EPL is deemed to have a worse performance than unemployment insurance as the adjustment to new conditions is expected to require significantly more labour reallocation (Bertola and Boeri, 2003). Unemployment benefits are also preferable to EPL on the grounds that they allow workers to seek for jobs that are hard to get because they require more specialized skills (Acemoglu and Shimer, 1999).

However, moving along this trade-off is proving extremely difficult. An inventory 
of reforms available at the Fondazione Rodolfo Debenedetti website (www.frdb.org) suggests that reforms of employment protection have been parametric, involving only marginal groups of the workforce and have been enforced "at the margin", that is, only limited to new hires. This is confirmed by the updating of the OECD index of the strictness of employment protection for regular workers, displayed in Figure 2.2 (drawn from OECD, 1999): the EPL for "regular" workers (workers with permanent contracts) has hardly changed at all in OECD countries over the decade. The location of the different countries along the UB-EPL trade-off would seem to be a stable politicoeconomic equilibrium. Characterizing these equilibria is the task setup for the next sections.

\section{The Economic Model}

In our economy, agents are infinitely long lived. In every period, they consume their current income, since, as in Wright (1986), we assume that no saving technology is available $^{2}$. Their preferences are defined over the infinite stream of consumption, $c$, through a utility function, $\sum_{k=t}^{\infty} \beta^{k-t} v\left(c_{k}\right)$, where $\beta$ represents the individual time discount, and the instant utility function is assumed to be logarithmic: $v(c)=\ln (c)$.

Agents differ in their skill level. There are low and high skill types, $l$ and $h$, and $\rho_{j}$ is the fraction of the type- $j$ workers in the population. Clearly, $\rho_{l}+\rho_{h}=1$. Moreover, we assume that there are more low than high skill types, $\rho_{l}>\rho_{h}$. If employed, low skill workers earn a pre-tax real wage equal to $w^{l}$, while high skill workers earn $w^{h}$, with $w^{h}>w^{l}$. In every period, agents may be either employed or unemployed. According to the existing literature, we refer to the employed as "insiders" and to the unemployed as "outsiders". The transition between these two states is regulated by a Markov process, with type specific probability of transitions. In particular, $F^{j} \in(0,1)$ is the probability that a type- $j$ employed worker becomes unemployed (the unemployment inflow rate); and $H^{j} \in(0,1)$ is the probability that a type- $j$ unemployed worker finds a job (the unemployment outflow rate). Our analysis concentrates on steady states. Thus, for each group of agents the unemployment rate is $u^{j}=F^{j} /\left(H^{j}+F^{j}\right)$, while the total unemployment rate is $u=u^{l} \rho^{l}+u^{h} \rho^{h}$. Clearly, we have that $\partial u^{j} / \partial F^{j} \geq 0$ and $\partial u^{j} / \partial H^{j} \leq 0$. Moreover, stability conditions for the unemployment rate require that $F^{j}<H^{j} \forall j$.

\subsection{Labour Market Institutions}

We consider two types of labour market institutions: i) an unemployment benefit (UB) program, which in every period taxes the employed and provides a transfer to the

\footnotetext{
${ }^{2}$ This assumption greatly simplifies the analysis. Notice that the existence of perfect capital markets would be analogous to have risk neutral agents. A discussion of the effects of this assumption on the results is in section 4.4 .
} 
unemployed; and ii) an employment protection legislation (EPL), which reduces unemployment inflow (and outflow) rates.

Unemployment Benefits Our insurance program imposes a proportional tax, $\tau$, on the labour income of the workers and awards to any type- $j$ unemployed agent a transfer, $b^{j}$, proportional to her previous wage, hence to her type: $b^{j}=\alpha^{j} w^{j}$, where $\alpha^{j}$ is a replacement rate that measures the generosity of the scheme for each type. The system is budget balanced and thus the total amount of transfers to the unemployed equals the total contributions:

$$
b^{l} u^{l} \rho_{l}+b^{h} u^{h} \rho_{h}=\tau\left[w^{l} \rho_{l}\left(1-u^{l}\right)+w^{h} \rho_{h}\left(1-u^{h}\right)\right] .
$$

We impose two further restrictions to UBs. First, the tax rate on the labour income has to be lower than the unemployment rate of both types: $\tau<\operatorname{Min}\left(u^{l}, u^{h}\right)$. This condition guarantees that agents have an incentive to work, although in our model agents are not given an explicit labour-leisure decision. Second, we assume that $\alpha^{j}=\tau\left(1-u^{j}\right) / u^{j}$. The generosity of the UB system may differ across types, according to their unemployment rate. For instance, if high skill types have a lower unemployment rate than low skill types, they will obtain - per any given tax rate - a higher transfer when unemployed than the low-skill types. Notice that under this characterization, the UB system represents a pure unemployment insurance scheme which - for a given premium, the tax rate $\tau$-provides a larger benefit to those types who are less likely to become unemployed. In fact, by setting these different replacement rates, we abstract from any redistributive element between types. In section 4, we discuss how our result would be affected by using a unique replacement rate, thereby allowing for some redistribution, typically from high to low skill types. Finally, let $z^{j}=\left(1-u^{j}\right) / u^{j}=H^{j} / F^{j}$ be the ratio of type- $j$ employed to unemployed agents. Then, we have that $b^{j}=\tau w^{j} z^{j}$.

Employment Protection Legislation Labour markets may be regulated by a legislation protecting the workers against the risk of becoming unemployed. This legislation may take different forms. According to the OECD (1994), the measure of EPL can be decomposed in: (1) procedural inconveniences to dismissals (mainly capturing the complexity of the procedures needed to issue a dismissal notice); (2) notice and severance payments requirements (the time elapsed between the decision to layoff a worker and her/his effective removal from the payroll); and (3) difficulty of dismissals, which measures the relevance of litigation costs and any possible bias in the judicial enforcement process ${ }^{3}$. Cazes, Boeri and Bertola (1999) suggest that the third component of EPL - the difficulty of dismissal - accounts for most of the reduction in the dismissal

\footnotetext{
${ }^{3}$ To this respect, see Ichino, Polo and Rettore (2001).
} 


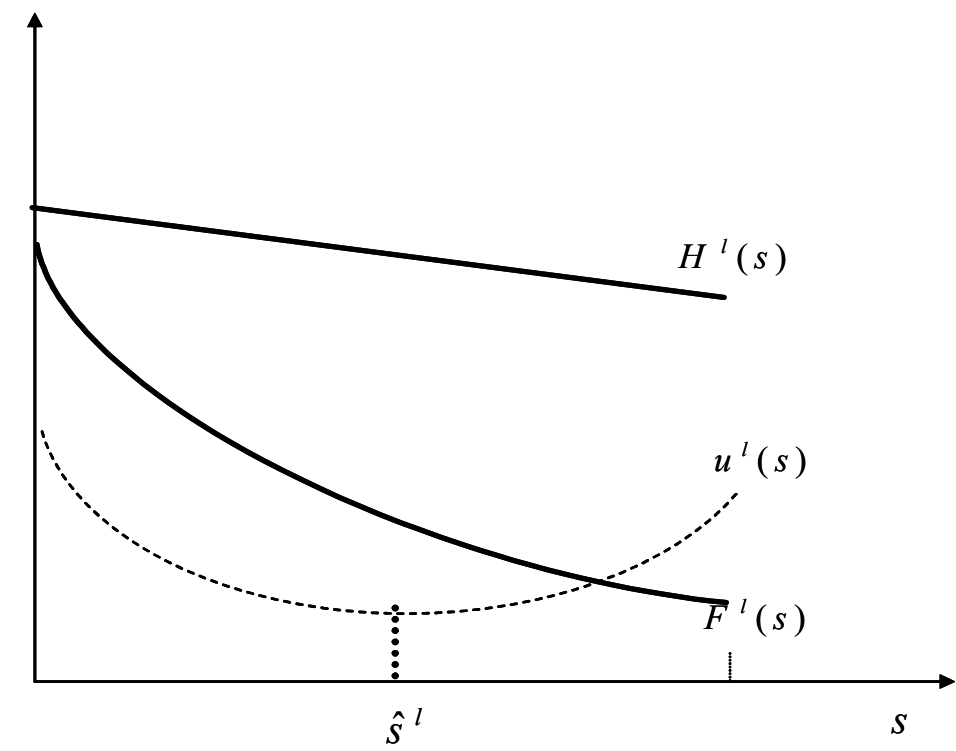

Figure 3.1: EPL and Low-skill Individuals

rate associated with stricter EPL. Accordingly, in our stylized framework, we simply characterize the EPL as a deadweight cost - such as litigation cost - while we disregard the existence of severance payments, and their possible role of insurance against the unemployment risk ${ }^{4}$.

In our model, the degree of EPL is thus measured by a parameter $s \in[0,1]$, where $s=0$ means no protection and $s=1$ denotes maximum protection. As in SaintPaul (1996 and 2000), we concentrate on the effects of EPL on unemployment inflow and outflow rates, on which there is little ambiguity in the empirical and theoretical literature on EPL. Consider the low skill types. A higher degree of EPL decreases the unemployment inflow rate, $F_{1}^{l}(s) \leq 0$, as widely documented by OECD (1999) and Boeri (1999) Consistently with empirical evidence reviewed in section 5, we assume that this effect is larger when the labour market is flexible $(s \simeq 0)$ than under strict $\mathrm{EPL}^{5}$,

\footnotetext{
${ }^{4}$ As shown by Lazear (1990), under flexible wages, severance payments can be "undone" by wage contracts "bonding" the duration of a job.

${ }^{5}$ It can be shown (results can be provided upon request by the authors) that Mortensen and Pissarides' (2001) equilibrium search model also yields a convexity of the reservation productivity (hence unemployment inflows) in EPL, provided that the matching function is specialised as a Cobb-Douglas. This model also implies a negative effect of EPL on unemployment inflows and outflows. In the case of outflows, however, it is not possible to establish a priori the sign of the second derivative.
} 
i.e., $F_{11}^{l}(s)>0$.

Also the unemployment outflow rate is negatively related to the strictness of EPL, $H_{1}^{l}(s)<0$, in accordance with empirical evidence (OECD, 1999) and with the implications of economic models of EPL (e.g., Bentolila and Bertola, 1990) which suggest that in rigid labour markets employers are less willing to hire workers in upturns, because they will not be able to dismiss them during downturns. Figure 3.1 summarizes the behavior of the low skill inflow and outflow rates as a function of the strictness of EPL. Notice that a trade-off arises since more EPL decreases the unemployment inflow of low skill types, while reducing their outflow. The overall effect on the unemployment rate is therefore ambiguous, as in standard equilibrium models of the labour market (Mortensen and Pissarides, 2001). Provided that unemployment inflows are negative and convex in EPL, while unemployment outflows are linear (declining) in EPL, we expect unemployment to be decreasing for low levels of employment protection (as the effect on the inflow side dominates) and increasing for larger values of $s$ (as the effect on the outflow side becomes relatively more important) ${ }^{6}$. Thus, following Persson and Tabellini (2000), we assume that the unemployment rate is first decreasing and then increasing in the degree of $\mathrm{EPL}^{7}$, and has an interior minimum at $\widehat{s}^{l}$.

High skill types are less affected by the EPL. On the one hand, part of the costs of EPL arises from red-tape negotiation costs with the unions and union density is traditionally low among high-skill types. On the other hand, EPL involves fixed costs, i.e. litigation costs, which are independent of the worker's type. Thus, EPL is less of a deterrent when employers plan to layoff high skill workers, provided that in recessions the marginal productivity of a worker is close to zero. Several general equilibrium models of the labour market (e.g., Mortensen and Pissarides, 2001) yield this result when firing costs are independent of the worker's type.

For analytical convenience, we take the rather extreme view that EPL leaves the high types unaffected, i.e., $F^{h}$ is a constant in our model. However, we assume that the unemployment outflow rate is negatively related to the strictness of EPL also for the high-skill types, $H_{1}^{h}(s)<0$. This is consistent with the observation of negative effects of EPL on job finding probabilities of school-leavers (OECD, 1999). Overall, in our model EPL is only harmful to the high skill insiders: the degree of EPL which minimizes the unemployment rate of the high skill types is zero, $\widehat{s}^{h}=0$, as shown in figure 3.2 .

Finally, consistently with a large body empirical evidence on hazards from employ-

\footnotetext{
${ }^{6}$ Consider that $u=\left(\frac{F}{H+F}\right)$, where we have dropped skill-superscripts for notational ease. It then follows that $u_{s} \gtreqless 0$ depending on whether $\left|F_{s}\right| H \lesseqgtr F\left|H_{s}\right|$.

${ }^{7}$ Notice that the assumptions that (i) the inflow rate is decreasing and convex in the degree of EPL, $F_{1}^{l}<0$ and $F_{11}^{l}>0$, and (ii) that the outflow rate is a linear, non-positive function of the EPL, $H_{1}^{l}<0$ and $H_{11}^{l}=0$, are sufficient for the unemployment rate to have a minimum, although the unemployment rate needs not to be convex in $s$.
} 


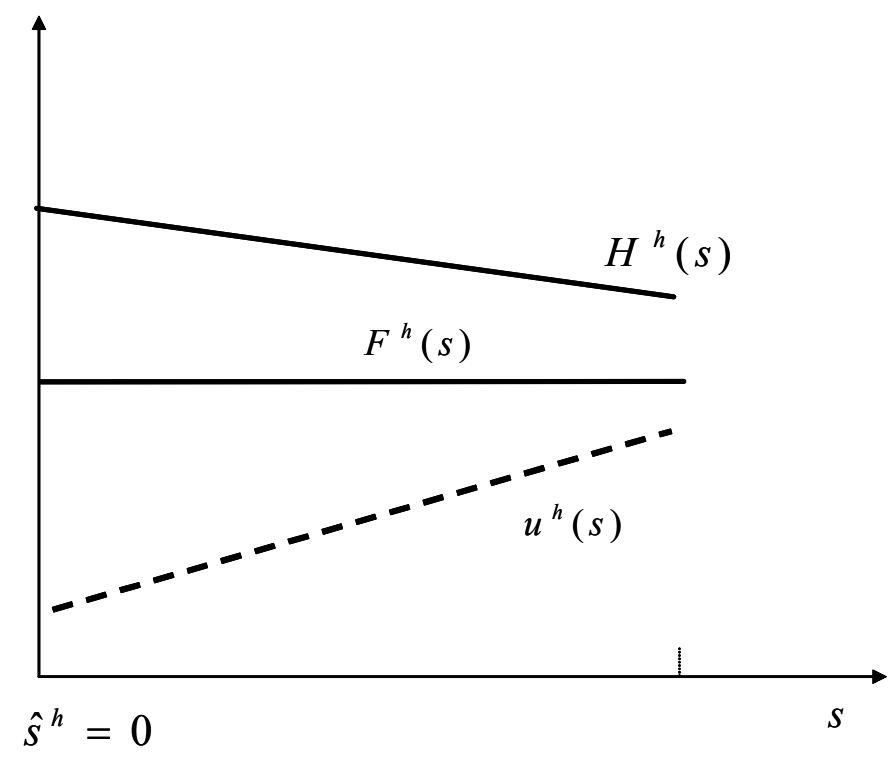

Figure 3.2: EPL and High-skill Individuals

ment to unemployment and viceversa, we assume that the unemployment inflow rate is always higher for the low than for the high skill workers ${ }^{8}, F^{l}(s=0) \geq F^{h}$, and that, for any degree of EPL, the unemployment outflow rate of the high skill workers is higher than the outflow rate of the low skill ones, $H^{l}(s) \leq H^{h}(s) \forall s$. Evidence supporting this modeling strategy is provided in Section 5.

\subsection{Individual Preferences}

As in Wright (1986) and Pissarides (2001), in our model individuals cannot save to insure against the risk of becoming unemployed. Thus, in every period, the level of consumption for each skill type is entirely determined by her employment status. If employed, a type $j$ agent consumes $(1-\tau) w^{j}$; if unemployed, she consumes $b^{j}$. It is useful to denote the difference in utility between the two labour market stata for a type- $j$ agent as $\Delta v^{j}=v\left((1-\tau) w^{j}\right)-v\left(b^{j}\right)>0$. We can now characterize the indirect utility function with respect to the degree of EPL and UB. Let $V_{i}^{j}(s, \tau)$ denote the expected

\footnotetext{
${ }^{8}$ This assumption captures the difference in the job-to-job reallocation between low and high ability types. In fact, high ability types tend to have more job-to-job mobility and a lower unemployment inflow rate than the low-ability types. Additionally, high-ability workers have more firm specific human capital, which reduces incentives of employers to fire them.
} 
lifetime utility of a type- $j$ agent when she is currently in state $i$. Then $V_{O}^{j}(s, \tau)$ is the expected lifetime utility of a type- $j$ agent who is currently unemployed - an outsider and $V_{I}^{j}(s, \tau)$ is the utility of a currently employed agent- an insider. Since the expected utility depends only on the state, and not on the date, we have that:

$$
V_{i}^{j}(s, \tau)=\frac{\left(1-\theta_{i}^{j}(s)\right) v\left((1-\tau) w^{j}\right)+\theta_{i}^{j}(s) v\left(b^{j}\right)}{(1-\beta)}
$$

where

$$
\theta_{O}^{j}(s)=\frac{1-\beta+\beta F^{j}}{1-\beta+\beta\left(F^{j}+H^{j}\right)}
$$

represents the (discounted) proportion of time that a type- $j$ agent who is currently an outsider will spend unemployed during her lifetime, while

$$
\theta_{I}^{j}(s)=\frac{\beta F^{j}}{1-\beta+\beta\left(F^{j}+H^{j}\right)}
$$

represents the (discounted) proportion of time that a type- $j$ agent who is currently an insider will spend unemployed, and again $j=h, l$. Clearly, $\theta_{O}^{j}(s)>\theta_{I}^{j}(s) \forall j$. It is useful at this juncture to define the degree of EPL which minimizes the (discounted) time spent unemployed respectively by a low-skill insider and outsider ${ }^{9}: \widetilde{s}_{I}=\arg \min \theta_{I}^{l}(s)$ and $\widetilde{s}_{O}=\arg \min \theta_{O}^{l}(s)$. It is easy to see that $\widetilde{s}_{O}<\hat{s}^{l}<\widetilde{s}_{I}$ - where $\hat{s}^{l}$ is the degree of EPL which minimizes unemployment among low-skill types - since $\widetilde{s}_{O}$ and $\widetilde{s}_{I}$ take into account the current employment status of the agent. Figure 3.3 summarizes the behavior of $\theta_{I}^{l}(s), \theta_{O}^{l}(s)$, and $u^{l}$ with respect to $s$. Finally, notice that as $\beta$ approaches 1 , current employment conditions lose their relevance and the indirect utilities of a type- $j$ insider or outsider coincide: $\theta_{I}^{l}(s)=\theta_{O}^{l}(s)=u^{l}$.

\section{The Political Game}

The degree of EPL and the level of UB are decided at majority voting. When the election takes place, all persons alive, employed and unemployed, cast a ballot over $\tau \in[0,1]$, the income tax which finances the unemployment insurance, and $s \in[0,1]$, the degree of EPL. Individual preferences over the two issues are represented by the indirect utility functions at equation 3.1, further characterized at equations 3.2 and 3.3 respectively for the outsiders and the insiders. This majoritarian voting game shares an important features with the games analyzed in Conde-Ruiz and Galasso (1999 and 2003). The issue

\footnotetext{
${ }^{9}$ Again, the assumptions on $F^{l}(s)$ and $H^{l}(s)$ - see footnote 7 - are sufficient for $\theta_{I}(s)$ and $\theta_{O}(s)$ to have a minimum, albeit not to be convex.
} 


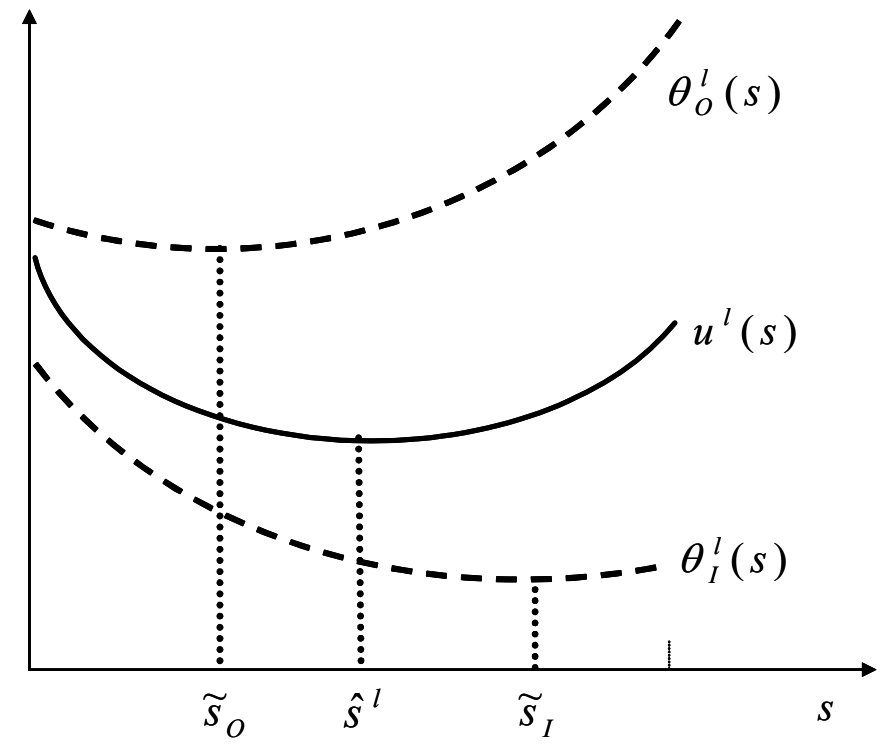

Figure 3.3: EPL: Low-skill Insiders and Outsiders

space is bidimensional, $(\tau, s)$, and thus a Nash equilibrium typically fails to exist. To overcome this well-known problem, we follow Shepsle (1979), and more recently Persson and Tabellini (2000), in analyzing voting equilibria induced by institutional restrictions, i.e., structure-induced equilibria. Conde-Ruiz and Galasso (1999 and 2003) discuss the set of institutional restrictions, which are needed to convert a two-dimensional election into a (dynamic) simultaneous issue-by-issue voting game, in which a (structure induced) equilibrium exists. The concept of structure induced equilibrium - or issue-by-issue voting - applied to our political game can be summarized as follows. For every value of $s$, the degree of EPL, each voter determines her most preferred value of $\tau$, the level of $\mathrm{UB}$, and viceversa. In other words, every agent votes two reaction functions: $\tau(s)$ and $s(\tau)$. A pair $\left(\tau^{*}, s^{*}\right)$ is an equilibrium of this voting game if $\tau^{*}$ represents the outcome of a majority voting over the jurisdiction $\tau$ - the level of employment benefit - when the other dimension is fixed at its level $s^{*}$, and viceversa. Finally, we restrict ourselves to a steady state analysis and assume that the voting game takes place once and for all. Re-voting, as in Conde-Ruiz and Galasso (1999 and 2003), would allow to capture some dynamic aspects of the game, but at the cost of further complicating the analysis of the political equilibrium. We now turn to the voting game by examining the agents' decisions over the EPL for a given $\tau$ and then the decisions over the UB for a given $s$. 


\subsection{Voting over the degree of Employment Protection Legislation}

EPL affects the utility of the agents through its effects on the unemployment inflow and outflow rates. As discussed in the previous section, high skill agents - either insiders or outsiders - oppose any positive level of EPL, which decreases their unemployment outflow rate but does not decrease their inflow rate. The choice of the low-skill agents is more complex, since the EPL creates a trade-off between their inflow and outflow rates. To see this, consider a low-skill insider. An increase in the degree of EPL has two effects on her indirect utility (see eq. 3.1). First, it has an impact on the (discounted) percentage of time that a current insider will spend unemployed during her lifetime, $\theta_{I}^{l}(s)$. Since the utility is larger when employed, this effect is positive for $s<\widetilde{s}_{I}$ - where $\widetilde{s}_{I}$ represents the degree of EPL that minimizes $\theta_{I}^{l}(s)$ - becomes zero at $s=\widetilde{s}_{I}$, and then turns negative, see figure 3.3. Second, an increase in the strictness of EPL has an impact on the unemployment benefit, through changes in the ratio of low skill employed to unemployed agents. This effect is positive for $s<\hat{s}^{l}-$ where $\widehat{s}^{l}$ represents the degree of EPL that minimizes the unemployment rate for the low skill $u^{l}(s)$ - and weakly negative thereafter. Therefore, a low-skill insider chooses a degree of EPL between $\widehat{s}^{l}$ and $\widetilde{s}_{I}$, since she trades off the current positive effect of a decrease in the unemployment inflow rate, with the future negative impact on the average unemployment rate, and thus on the level of UBs, see figure 3.3. A low skill outsider faces a similar problem. The latter effect coincides with the low-skill insider's decision. However, the former is positive for $s<\widetilde{s}_{O}<\widetilde{s}_{I}$ - where $\widetilde{s}_{O}$ is the degree of EPL which minimizes $\theta_{O}^{l}(s)$, the (discounted) fraction of time that a current outsider spends unemployed during her lifetime - becomes zero at $s=\widetilde{s}_{O}$, and then turns negative. Therefore, a low-skill outsider will choose a level of EPL between $\widetilde{s}_{O}$ and $\widehat{s}^{l}$, which best trades off the decrease in the average unemployment rate with the reduction in the current probability of being hired. The next proposition characterizes the decision of the median voter, $s^{m}(\tau)$.

Proposition 4.1. If $\left[1-u^{l}\left(s_{I}^{l}\right)\right] \rho^{l} \geq \frac{1}{2}$, the median voter over the jurisdiction $s$ is a low skilled insider, and the corresponding degree of EPL is $s^{m}(\tau)=s_{I}^{l}(\tau) \in\left(\widehat{s}^{l}, \widetilde{s}_{I}\right)$. If $\left[1-u^{l}\left(s_{O}^{l}\right)\right] \rho^{l}<\frac{1}{2}$, the median voter over the jurisdiction $s$ is a low skilled outsider, and the corresponding degree of EPL is $s^{m}(\tau)=s_{O}^{l}(\tau) \in\left(\widetilde{s}_{O}, \widehat{s}^{l}\right)$.

The median voter over the degree of EPL is a low-skilled agent. If - for the (high) degree of EPL chosen by a low-skill insider - the low-skill insiders are a majority, the median voter over $s$ is clearly a low-skill insider; whereas if - for the (low) degree of EPL chosen by a low-skill outsider - the low-skill insiders are a minority, the median voter over $s$ is a low-skill outsider ${ }^{10}$. The latter case is interesting, because it suggests

\footnotetext{
${ }^{10}$ Notice that both equilibria may fail to exist if - in the former case - the degree of EPL is too high and leads to large unemployment or if - in the latter case - it is too low and does not create enough
} 
that low skill outsiders play a pivotal role in deciding over the degree of EPL, although they do not benefit from it, at least in their current state.

How does the degree of EPL chosen by the median voter depend on the level of $\mathrm{UB}^{11}$ ? If the median voter is a low-skill insider, $s^{m}(\tau)=s_{I}^{l}(\tau)$, there is a negative relation between EPL and UB. In other words, for this median voter the reaction function of $s$ with respect to $\tau$ is negatively sloped, see figure 4.1. This result hints at some substitutability between EPL and UB as instruments to protect against labour market risk. In fact, a higher level of unemployment insurance reduces the cost, in terms of consumption, of being unemployed, and thus a low-skill insider will require a lower degree of EPL. However, if the median voter is a low-skill outsider, $s^{m}(\tau)=s_{O}^{l}(\tau)$, the relation between EPL and UB becomes positive, and thus the reaction function $s_{O}^{l}(\tau)$ is positively sloped, see figure 4.1. This is because an increase in the tax rate, $\tau$, reduces the current cost of being unemployed and thus induces the low-skill outsider to increase the degree of EPL in order to decrease the average unemployment rate and thus to increase the unemployment benefit (recall that $s_{O}^{l}(\tau)<\widehat{s}^{l}$ ).

\subsection{Voting over Unemployment Benefits}

Low and high skill individuals, according to their current employment status, determine their most preferred level of UB, by maximizing their indirect utility function with respect to the tax rate, $\tau$, for a given $s$. As in Wright (1986), the most preferred tax rate for a type- $j$ insider is $\tau_{I}^{j}(s)=\theta_{I}^{j}(s)$ (see equation 3.3), and for a type- $j$ outsider is $\tau_{O}^{j}(s)=\theta_{O}^{j}(s)$ (see equation 3.2 ), where $j=l, h$. These tax rates are decreasing in the unemployment outflow rate and increasing in the inflow rate, since a lower (higher) probability of being unemployed induces a lower (higher) demand for unemployment insurance. In order to find the median voter over UB, we need to compare these tax rates ${ }^{12}$. Among the insiders, the low skill have a higher probability of becoming unemployed and a lower outflow rate. Thus, they prefer a higher tax rate than the high skill workers, $\tau_{I}^{l}(s) \geq \tau_{I}^{h}(s)$. A similar reasoning applies to the outsiders, hence $\tau_{O}^{l}(s) \geq \tau_{O}^{h}(s)$. Additionally, for a given skill type $j$, the outsiders prefer a higher tax rate than the insiders, due to their current status, and thus $\tau_{O}^{j}(s)>\tau_{I}^{j}(s)$. Although we are not able to provide a complete ordering of the preferences of the agents over the UB tax rate, the next proposition characterizes the median voter over $\tau$, and thus the tax rate that she prefers for a given $s$.

\footnotetext{
unemployment.

${ }^{11}$ Lemma A.1 in the appendix provides a formal answer.

${ }^{12}$ Clearly, if the UB scheme entails some element of redistribution across types - such as in a Beveridgean system, where the benefits are flat, or in an "unfair" insurance scheme, where the replacement rate is constant across types, regardless of their unemployment risk - the voting behavior would change. See discussion in section 4.4 and appendix B.
} 
Proposition 4.2. If $u \leq 1 / 2$, the median voter over the unemployment tax rate is a low skill insider, and the corresponding tax rate is $\tau^{m}(s)=\tau_{I}^{l}(s)=\theta_{I}^{l}(s)$.

Except in the extreme case in which the unemployed constitute a majority of the population, the low skill insiders are pivotal in determining the level of unemployment insurance. Taken together with the previous results on the degree of EPL, this suggests that most of the political power rests in the hands of the low skill insiders, who set the UB level and are likely to decide over the degree of EPL.

How does their choice over UB depend on the degree of EPL? As shown in figure 3.3, the tax rate, $\tau^{m}(s)=\tau_{I}^{l}(s)=\theta_{I}^{l}(s)$, is first decreasing and then increasing in the degree of EPL (see Lemma A.2 in the appendix for a proof). The intuition is straightforward. For low degrees of EPL, an increase in $s$ reduces the average unemployment rate of a low-skill agent as well as her unemployment inflow rate. Thus, a low skill insider is more protected against the risk of being unemployed, requires less UB, and $\tau$ decreases. Once the degree of EPL is larger than $\widehat{s}^{l}$, any additional increase of EPL raises the average unemployment rate, but this effect is compensated by a reduction in the unemployment inflow rate, and thus the demand for UB still declines. However, beyond $\widetilde{s}_{I}-$ the degree of EPL which minimizes the (discounted) percentage of time spent unemployed by a current insider - the negative effect on the unemployment rate becomes dominant, a low skill insider is more likely to become unemployed and her demand for UB begins to increase.

\subsection{The Political Equilibria}

To find the political equilibria of our voting game over the degree of EPL, $s$, and the level of UB, $\tau$, we need to bring together the voting behavior over $s$ and $\tau$ in our issueby-issue voting game. The (structure-induced) equilibrium outcomes of this voting game correspond to the loci where the reaction function of the two median voters characterized respectively in sections 4.1 and 4.2 - cross, and are described in the next proposition:

Proposition 4.3. (I) If $\left[1-u^{l}\left(s_{I}^{l}\right)\right] \rho^{l} \geq \frac{1}{2}$, there typically exists a structure-induced equilibrium (SIE) of the voting game $\left(\tau^{*}, s^{*}\right)$, such that $\tau^{*}=\tau_{I}^{l}\left(s_{I}^{l}\right)$ and $s^{*}=$ $s_{I}^{l}\left(\tau_{I}^{l}\right) \in\left(\widehat{s}^{l}, \widetilde{s}_{I}\right)$;

(II) If $\left[1-u^{l}\left(s_{O}^{l}\right)\right] \rho^{l}<\frac{1}{2}$, there typically exists a structure-induced equilibrium (SIE) of the voting game $\left(\tau^{* *}, s^{* *}\right)$, such that $\tau^{* *}=\tau_{I}^{l}\left(s_{O}^{l}\right)$ and $s^{* *}=s_{O}^{l}\left(\tau_{I}^{l}\right) \in\left(\widetilde{s}_{O}, \widehat{s}^{l}\right)$.

(III) If $\left(\tau^{*}, s^{*}\right)$ and $\left(\tau^{* *}, s^{* *}\right)$ exist, then $s^{* *}<s^{*}$ and $\tau^{* *}>\tau^{*}$.

This proposition contains the crucial theoretical result of the paper. If the low skill insiders constitute a majority of the voters, they determine both the degree of EPL 


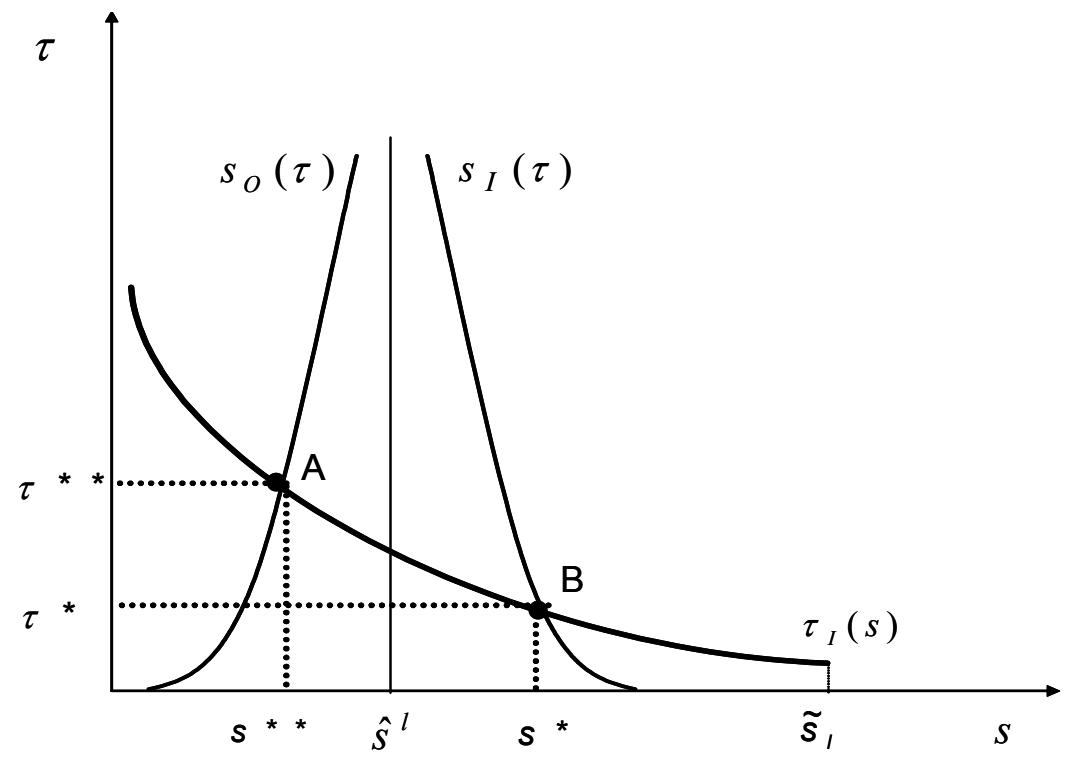

Figure 4.1: Two structure-induced equilibria and the trade-off UB-EPL

and the level of UBs. This case is geometrically characterized in Figure 4.1, where the two reaction functions, $\tau_{I}^{l}(s)$ and $s_{I}^{l}(\tau)$, are portrayed. Even if the low-skill are not a majority, they are still pivotal in choosing UBs, and thus the relevant reaction function is still $\tau_{I}^{l}(s)$. In this case, if there are enough unemployed individuals, the lowskill outsiders are pivotal in deciding over the EPL and the relevant reaction function becomes $s_{O}^{l}(\tau)$ (see figure 4.1). The last part of this proposition accounts for the existence of a trade-off between UB and EPL, depending on the skill composition in the economy. A large fraction of low-skill types creates a large support in favour of EPL, but then, this large degree of employment protection decreases the demand for UB. In economies with a large share of high skill individuals (case II), the support for EPL is reduced. Lower degrees of EPL in turn induce - among the low skill insiders, who are still pivotal in the UB decision - a higher demand for UB. In the next section, we assess empirically the link between this trade-off and the skill profile of the population.

Could a trade-off emerge even among countries with a majority of low-skill insiders? The next proposition addresses this issue by examining how the equilibrium outcome in case I at proposition 4.3 is affected by a change in the subjective rate of time discount.

Proposition 4.4. For $\left[1-u^{l}\left(s_{I}^{l}\right)\right] \rho^{l} \geq \frac{1}{2}$, a decrease in $\beta$ induces a change in an equilibrium outcome from $\left(\tau^{*}, s^{*}\right)$ to $\left(\tau^{* \prime}, s^{* \prime}\right)$, such that $\tau^{* \prime}<\tau^{*}$ and $s^{* \prime}>s^{*}$. 
If the low-skill insiders assign greater weight to their present status (as $\beta$ decreases), they will require less UBs, but more EPL. This insight carries a powerful testable implication, namely in countries with an older population of low-skill insiders who discount the future employment status more heavily, we should observe stricter EPL and less generous UBs. Analogously, the existence of early retirement provisions, which guarantee an early exit from the labour market to middle-aged workers, reduces the relevance of the future employment opportunities, and thus puts more pressure on increasing restrictions on dismissals.

\subsection{Discussion and Extensions}

The results of our baseline model, notably the existence of a trade off between EPL and $\mathrm{UB}$, are robust to several extensions of the model. In this section, we consider three alternative specifications to discuss the effects of changes in the degree of risk aversion, the impact of unemployment benefit programs on the unemployment outflow rate, and to examine a redistributive unemployment benefit program ${ }^{13}$.

Risk aversion plays a key role in our analysis, since UB and EPL help to insure against labour market risks. Clearly, more risk averse agents require more insurance against unemployment risk: for any given degree of EPL, a low-skill insider will hence demand a higher tax rate, $\tau$. The effect of an increase in risk aversion on the voting behavior over the EPL is less straightforward. More risk averse individuals care more about consumption when unemployed. Hence, to increase UBs - by reducing the average unemployment rate - a low skill insider will decrease her preferred degree of EPL, while a low skill outsider will increase it (see figure 3.3). Thus, for any given level of risk aversion, the trade off between EPL and UB always exists - see figure B.1 in the appendix. The degree of risk aversion does however affect our politico-economic equilibria. In fact, if the median voter (over EPL) is a low-skill insider, more risk aversion induces a substitution of EPL with UB, while if the median voter (over EPL) is a low-skill outsider, an increase in the degree of risk aversion increases the EPL and has an ambiguous impact on the tax rate. To the extent that individuals can self-insure against labour market risk by having access to capital markets ${ }^{14}$, we can expect a nearly risk-neutral behaviour in the choice over UB and EPL to prevail in countries with large capital markets. Thus, this implication of our model is in line with the existence of an asymmetry between the US, or more broadly Anglo-Saxon countries, and the other European countries, with the former countries experiencing lower EPL and UBs then the EU average.

\footnotetext{
${ }^{13}$ These results are compared to those obtained in the baseline model of the previous section. A more thorough treatment of these alternative specifications is in the appendix.

${ }^{14}$ When capital markets are more developed, voters have an additional channel to buy insurance against labour market risk by having access to capital markets (e.g., Bertola, 1999 and Pissarides, 2000).
} 
A large empirical literature has pointed out how the provision of UBs may disincentive job search (see the surveys by Atkinson and Micklewright, 1991 and Krueger and Meyer, 2002). In this second extension of our model, we address this issue by assuming that the low-skill unemployment outflow rate is negatively related to the tax rate ${ }^{15}$, $\tau$, which finances UBs: $H_{2}^{l}(s, \tau)<0$. Although this extension introduces substantial modifications to the structure of the model (see appendix B), the agents' voting behavior is only marginally affected ${ }^{16}$ and a trade off between the degree of EPL and the generosity of unemployment benefits still arises, depending on the skill composition of the economy.

Finally, we consider an unemployment benefit program, which imposes a proportional tax, $\tau$, on labour income, and awards a flat transfer, $b$, to every unemployed agent. As in the baseline case, this system is budget balanced and thus the total amount of transfers to the unemployed equals the total contributions. Clearly, this new system redistributes across skill types, since contributions depend on individual's labor income, and hence types, while benefits do not. The existence of a redistributive component affects the agents' voting behavior over the degree of EPL through two channels. First, UB, and hence consumption when unemployment, increases for the low skill types while it decreases for the high skill individuals. Second, EPL becomes more relevant to the unemployed, as an increase in the degree of EPL reduces the employment rate of the high skill agents, and hence UB. Both effects induce low skill types to prefer less EPL. As in the baseline case ${ }^{17}$, two equilibria arise - depending on the skill composition of the population - one with low EPL and high UB and another one with high EPL and low UB. Interestingly, both equilibria display a lower degree of EPL and more UB than the baseline case.

\section{Empirical Relevance}

The purpose of this section is to assess the empirical relevance of i) the substantive hypotheses of the model, and ii) its implications.

\footnotetext{
${ }^{15}$ We are aware that the empirical literature finds no conclusive evidence on the influence on the tax rate on the outflow rate. Nevertheless, for analitical semplicity, we assume that the unemployment outflow rate depends on the tax rate, $\tau$, rather than on the unemployment benefit, $b$, since this modelling choice allows us to obtain closed form solutions.

${ }^{16}$ When voting on the tax rate financing $\mathrm{UB}$, the tax rate is always lower than in the baseline case, due to the additional negative effect of the tax rate on the outflow rate.

${ }^{17}$ When voting on the tax rate, the existence of a redistributive component gives raise to a substitution and an income effect. With our logarithmic utility function, these two effects cancel out.
} 


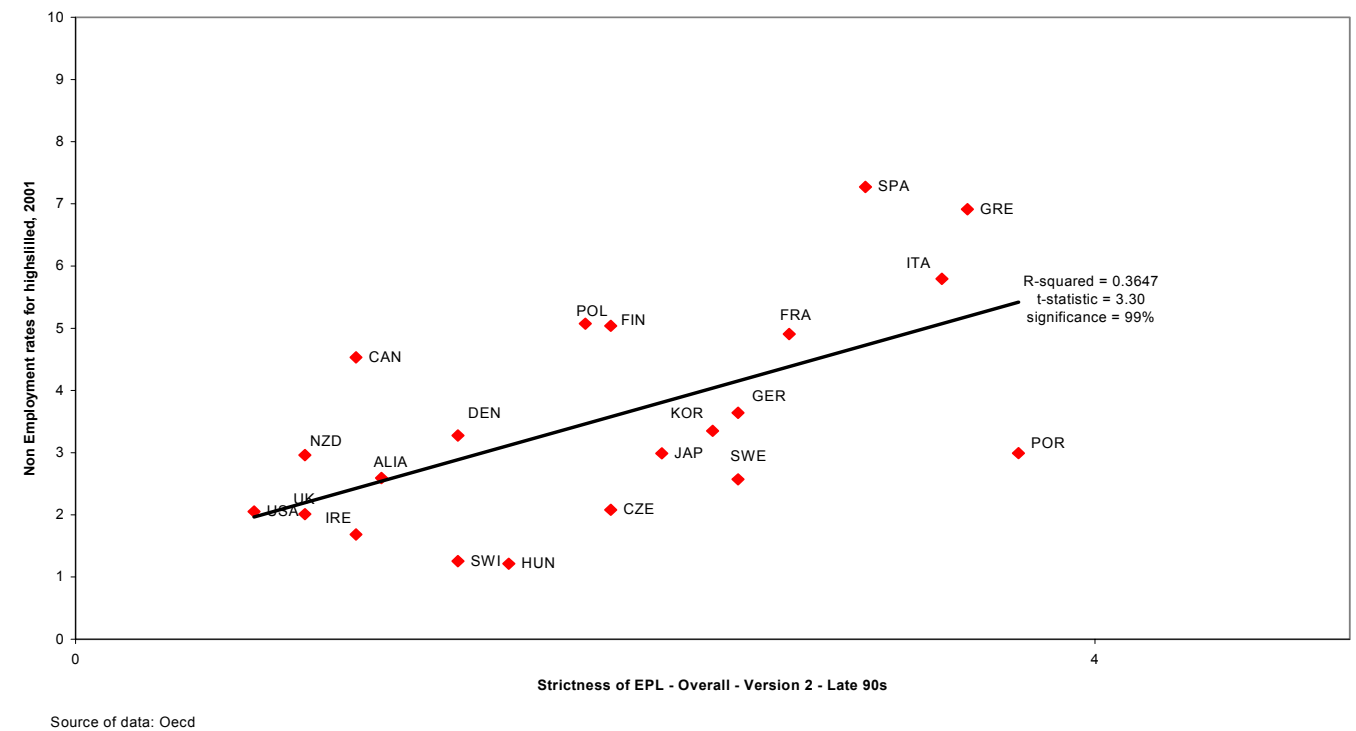

Figure 5.1: Non-Employment Rates and EPL: High-skill types

\subsection{EPL, Education and Unemployment Stocks and Flows}

Our key political economy results rest on the assumption that unemployment is Ushaped in EPL for the low-skill and always increasing in $s$ for the high-skill. In order to check the empirical relevance of these assumptions we proceed as follows. First, we define a partition of the population distribution by educational attainments such that more than $50 \%$ of the population is "unskilled" in all countries and the remaining part belongs to the high-skill group. This means grouping together the first 4 classes of the ISCED classification (educational attainment as high as upper secondary or below) as the "unskilled" and the remaining 3 classes as the high-skill (tertiary education) group. Second, we compute non-employment rates for these two groups. Although our simplified model assumes that everybody participates in the labour market, clearly EPL may also close-down the labour market for some skill levels (Mortensen and Pissarides, 2001). We thus choose to look at non-employment rather than unemployment. Third, we examine the relationship between EPL and labour market flows exploiting our comparable micro data on EU countries.

Figures 5.1 and 5.2 display the relationship between non-employment and EPL by education level. They suggest a clear (statistically significant) positive relationship 


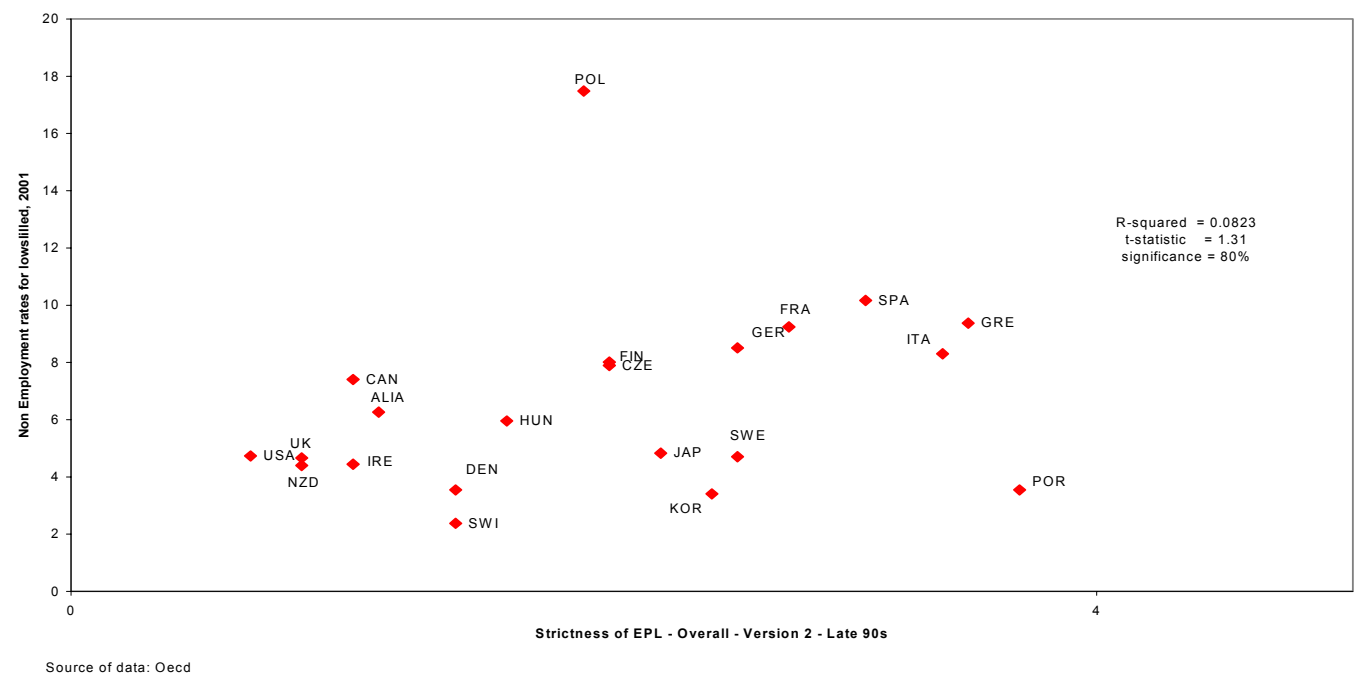

Figure 5.2: Non-Employment Rates and EPL: Low-skill types.

between non-employment rates and employment protection for the high-skill types, while there is not a significant relationship for the low-skill types (the linear regression is not significant at conventional levels). Fitting polynomials in the plot, one obtains a Ushaped pattern for the non-employment EPL relationship for this group.

Regarding the flows, two key assumptions of the model are that i) unemployment inflows are decreasing at a decelerating rate (convex) in the degree of EPL, and ii) the effects of EPL on unemployment inflows are stronger for low-skill types than for high-skill workers. Figures 5.3 and 5.4 display proxy quarterly job loss rates (defined as persons who are currently unemployed and who have been dismissed by their employer in the previous 3 months, as a proportion of dependent employment) and proxy hiring rates (persons currently employed, with a tenure lower than one-month, as a proportion of the working age population) by level of education. Average data for the period 1994-8 are drawn from the retrospective part of the ECHP questionnaire and plotted against the OECD index of employment protection discussed in Section 2.

In order to ease the reader, a second-degree polynomial is fitted into the correlogram. Three facts stand out. First, in line with the assumptions of our model, both unemployment inflow and outflow rates are declining in EPL. Second, the inflow rate for the low-skill types is (mildly) convex in employment protection. Third, job loss rates are less sensitive to EPL in the case of the high-skill types. These facts are in line with 
EPL overall VS unemployment inflows and hiring rates, for low education

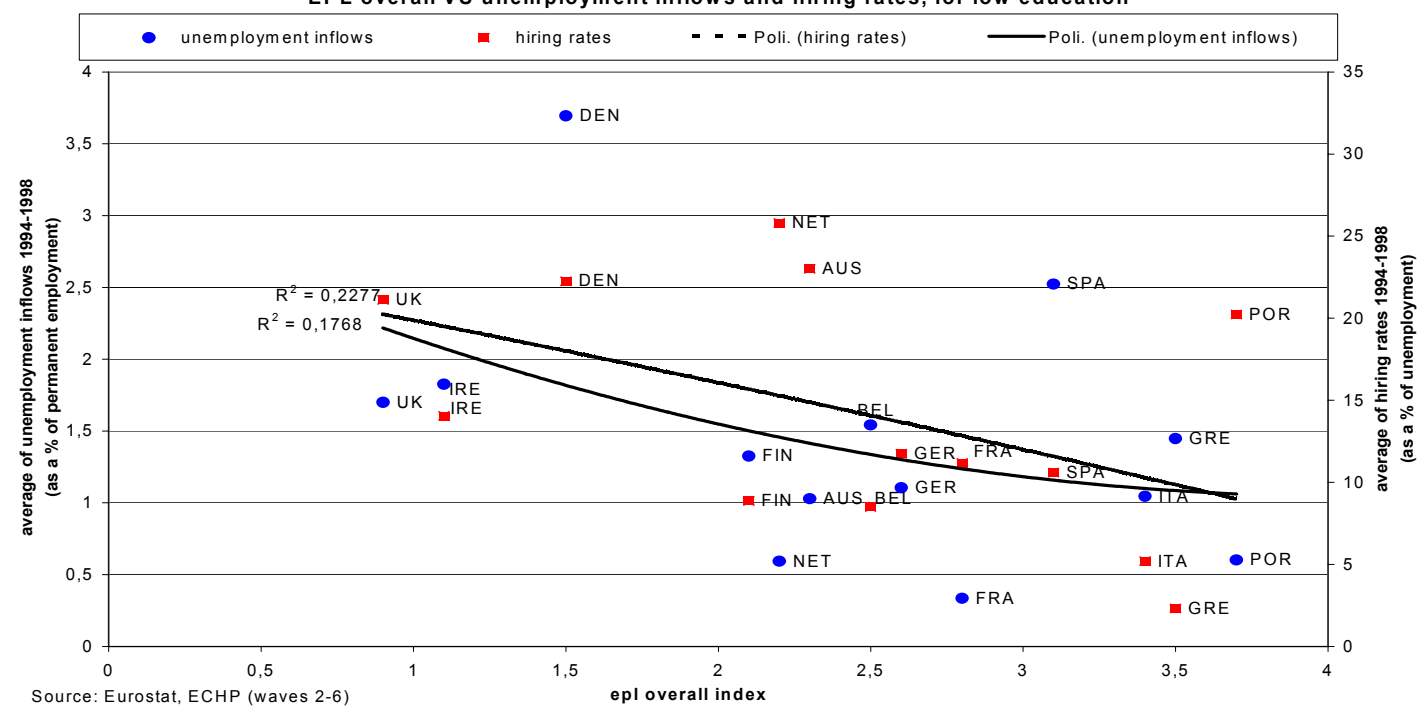

Figure 5.3: Unemployment Inflow and Outflow Rates: Low-skill Types

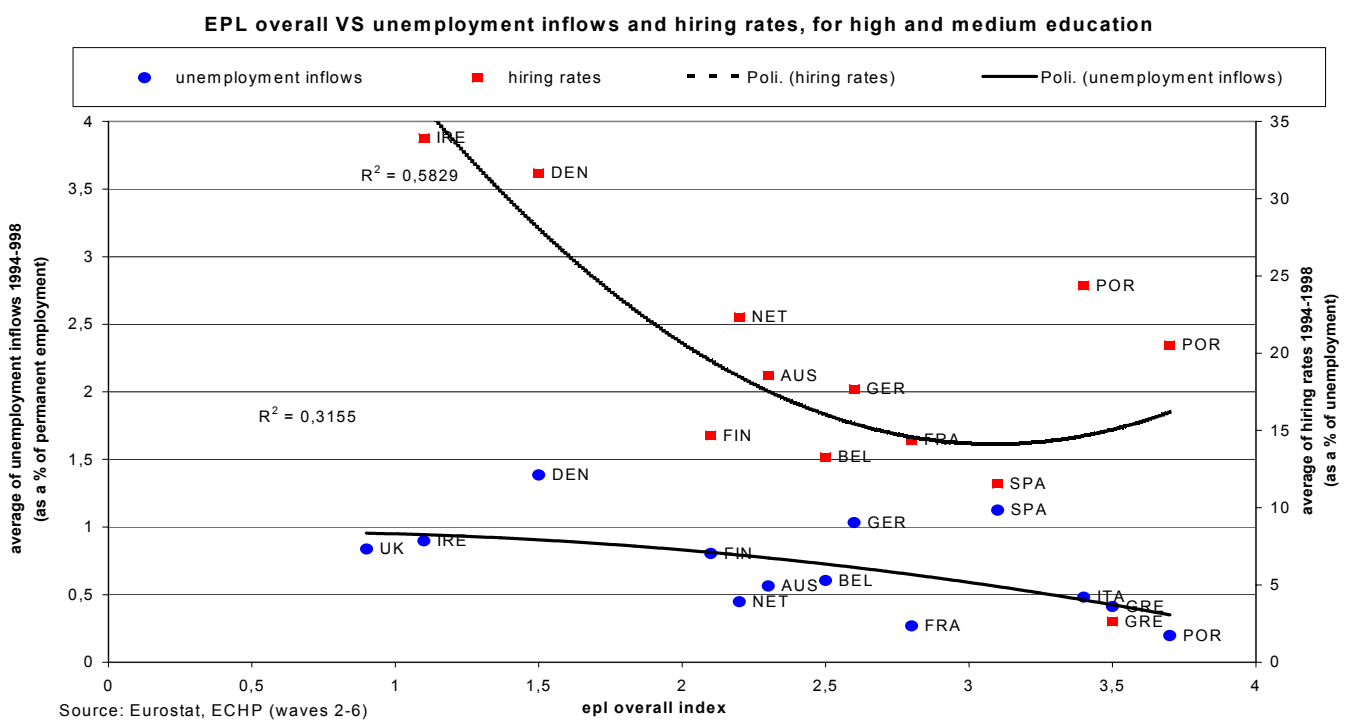

Figure 5.4: Unemployment Inflow and Outflow Rates: High-skill Types 
the assumptions of our model.

\subsection{Voting for EPL}

A survey carried out by Fondazione Rodolfo Debenedetti in April 2002 on a representative sample of Italians (1,000 individuals aged 16 to 80 ) yields insights as to the characteristics of the individuals voting in favor of stricter employment protection. All respondents were asked whether they preferred a flexible "labour market regime in which it is relatively easy to find a job, but it is likewise easy to loose a job" or a rigid labour market in which jobs are difficult to find but last longer. Table 5.5 displays the dprobit estimates of the probability of being in favour of a rigid labour market. Being aged more than 55 yields a 20 per cent higher probability (than the baseline) to vote in favour of employment protection. Low educational attainments also play in favour of EPL $(+12 \%)$ and even more so when interacted with the fact of having lost a job $(+40 \%)$. Residence in depressed labour markets (e.g., in the Mezzogiorno) also increases support to employment protection.

\subsection{Estimating the UB/EPL trade-off}

Finally, tables 5.6 and 5.7 display estimates of the UB/EPL trade-off across a panel of European countries. In particular, the dependent variable is the logarithm of the ratio of the measure of generosity of unemployment benefits and the OECD index of the strictness of employment protection discussed in Section 2. Table 5.6 focuses on the characteristics of insiders. In particular, it evaluates the effects on the UB/EPL configuration of a different skill composition of the workforce. The regression results suggest that a larger share of workers with secondary (the middle edu variable) and tertiary educational attainments (high edu) are associated with configurations assigning a larger weight to UB vs. EPL. The age structure of employment is also important: larger proportions of young people in employment yield institutional configurations attributing more importance to unemployment insurance with respect to employment protection. The existence of a well-developed capital markets, which provides an alternative way to protect against labour market risk, also induces less request for employment protection, while the effect of union density, which tentatively captures obstacles to wage adjustment, is not statistically significant.

A problem with this specification is that the skill and age composition of the employed are endogenous to the particular institutional configuration adopted by the various countries. In order to rule out reverse causality, e.g., the fact that countries with stricter EPL have lower employment rates among young people, in Table 5.7 we focus on the characteristics of the population in working age rather than of employed individuals only. The results are still in line with the implications of the model: a distribution 


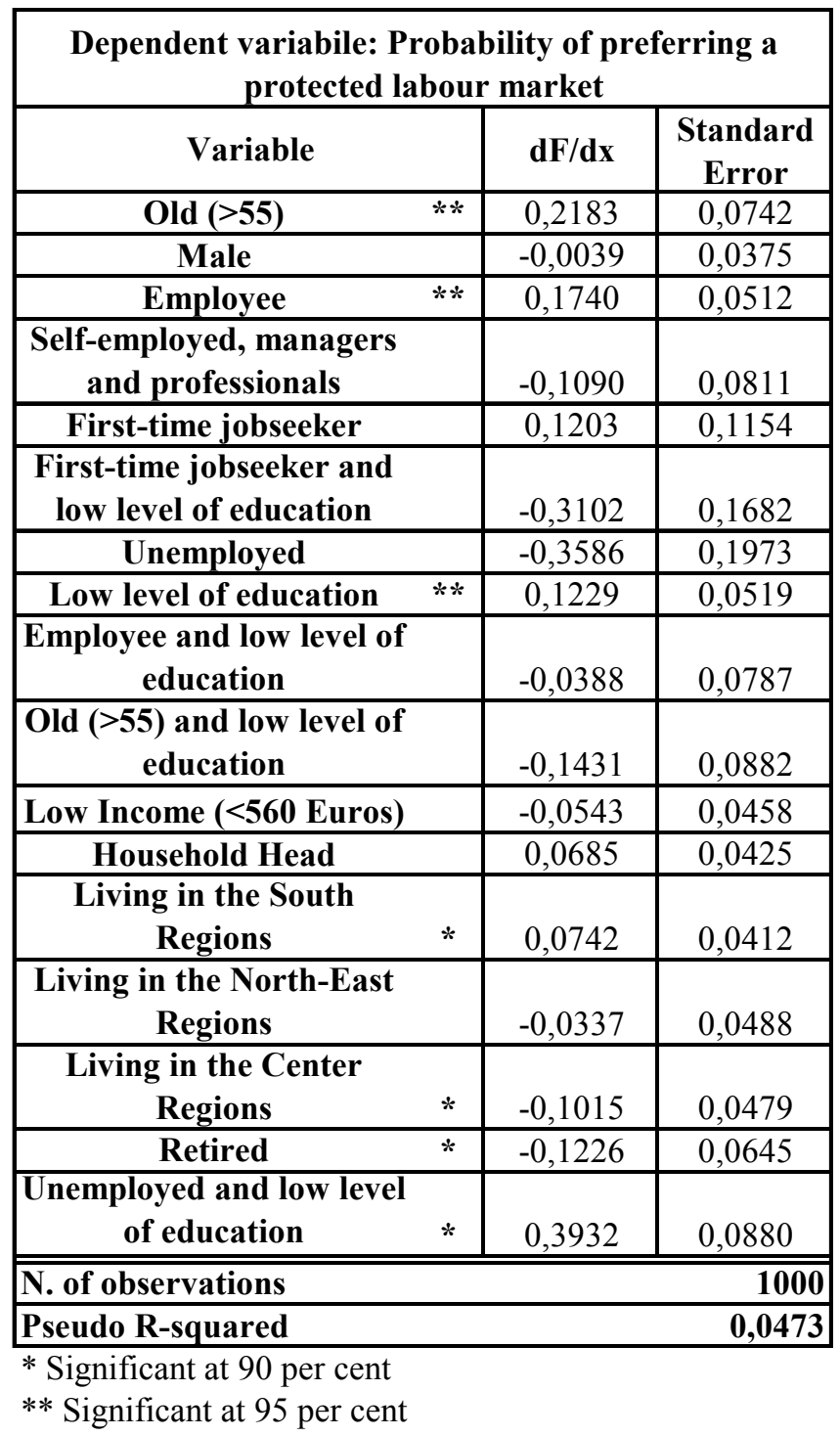

Figure 5.5: Voting on UB and EPL 


\begin{tabular}{|c|c|c|c|}
\hline \multicolumn{4}{|l|}{$\begin{array}{l}\text { Number of obs }=121 \\
\text { Prob }>\text { F }=0.0000 \\
\text { Adj R2 }=0.4851\end{array}$} \\
\hline $\log (\mathrm{ub} / \mathrm{epl})$ & Coefficient & Significance & Standard-Error \\
\hline market capitalisation & 0,003 & $* *$ & 0,002 \\
\hline share middle edu & 1,216 & $* * *$ & 0,451 \\
\hline share high edu & 5,563 & $* * *$ & 0,662 \\
\hline share of emp15_24 & 6,268 & $* * *$ & 2,011 \\
\hline share of emp55_64 & $-2,954$ & & 2,532 \\
\hline union density & 0,002 & & 0,002 \\
\hline dummy data & 2,683 & $* * *$ & 0,433 \\
\hline cons & $-5,218$ & $* * *$ & 0,559 \\
\hline
\end{tabular}

Figure 5.6: The Trade-off and the Characteristics of Insiders

of skill types more skewed towards highly or medium-skill individuals yields equilibria assigning more weight to UB vs EPL. Interestingly, in this case we find a significant effect also of the ageing variable: a larger share of individuals aged 55-to-64 involves stricter EPL and/or lower generosity of UB. Stock market capitalization - a measure of the scope of capital markets - also tend to favour institutional configurations with more UB and less EPL according to our estimates. To the extent that a larger scope of financial markets reduces the degree of risk-aversion involved in the choice between UB and EPL, this result is also in line with the implications of the extended version of our model.

\section{Conclusions}

European countries provide different types of insurance to workers against labour market risks, by combining different degrees of employment protection and unemployment insurance. A heated debate has been taking place over the need to reform some of the existing labour market institutions, and some form of consensus has emerged even among academics that Southern European countries should adopt institutional configurations assigning a greater weight to UB and less importance to EPL in protecting workers against labour market risk. However, reforming institutions along these lines is 


\begin{tabular}{|c|c|c|c|c|}
\hline \multicolumn{3}{|c|}{$\begin{array}{l}\text { Number of obs }=115 \\
\text { Prob }>\text { F }=0.0000 \\
\text { Adj R2 }=0.5384\end{array}$} & \multirow[b]{2}{*}{ Significance } & \multirow[b]{2}{*}{ Standard-Error } \\
\hline \multicolumn{2}{|c|}{$\log (u b / e p l)$} & Coefficient & & \\
\hline \multicolumn{2}{|c|}{ market capitalisation } & 0,004 & $* *$ & 0,002 \\
\hline \multicolumn{2}{|c|}{ share middle edu } & 1,310 & $* * *$ & 0,492 \\
\hline \multicolumn{2}{|c|}{ share high edu } & 4,196 & $* * *$ & 0,855 \\
\hline \multicolumn{2}{|c|}{ pop15_24/total } & 0,009 & & 0,006 \\
\hline \multicolumn{2}{|c|}{ pop55_64/total } & $-0,019$ & $* * *$ & 0,006 \\
\hline \multicolumn{2}{|c|}{ union density } & 0,004 & & 0,002 \\
\hline \multicolumn{2}{|c|}{ dummy data } & 1,902 & $* * *$ & 0,483 \\
\hline \multicolumn{2}{|l|}{ cons } & $-3,194$ & & 1,924 \\
\hline
\end{tabular}

Figure 5.7: The Trade-off and the Characteristics of Outsiders

proving difficult and politically costly.

In this paper we have shown that different institutional configurations can be interpreted as politico-economic equilibria, corresponding to different skill and age compositions of insiders and outsiders, to differences in the scope of capital markets and to design features of the unemployment benefit system, namely the redistribution from high-skill to low-skill types involved by UBs. Our empirical results are encouragingly in line with the key assumptions and with the implications of the model.

There is a political feasibility theorem which is inspired by our analysis. It states that reforms of employment protection need to trade labour market flexibility with state-provided unemployment insurance. Moreover, the trade-off is likely to become more favorable when educational attainments of the workforce are higher and when capital markets are deeper. Both developments tend to reduce the demand of EPL per any given level of unemployment insurance. 


\section{References}

[1] A. Atkinson, J. Micklewright (1991) Unemployment Compensation and Labour Market Transitions: A Critical Review, Journal of Economic Literature.

[2] D. Acemoglu, R. Shimer (1999) Productivity Gains from Unemployment Insurance, NBER Working Papers, n.7352.

[3] D. Acemoglu ,A., P. Aghion and G. Violante (2001) "Deunionization, Technical Change and Inequality", CEPR Discussion Paper, No.2764.

[4] Bentolila, S. and G. Bertola (1990), "Firing cost and labour demand: how bad is eurosclerosis?" Review of Economic Studies 57: 381-402.

[5] Bertola, G. and Boeri, T. (2003) EMU Labour Markets Two Years On: Microeconomics Tensions and Institutional Evolution, in Buti, M. and Sapir, A. (eds.) EMU and Economic Policy in Europe, Edward Elgar, 2002.

[6] Bertola, G., Boeri, T. and Nicoletti, G. (2000). (eds.) Welfare and Employment in a United Europe, MIT Press.

[7] Boeri, T. (1999) Enforcement of Employment Security Regulations, On-the-job Search and Unemployment Duration, European Economic Review, 43, 65-89.

[8] Boeri, T., A. Börsch-Supan and G. Tabellini (2001), "Would you like to shrink the welfare state? A survey of European citizens" Economic Policy April, 9-50.

[9] Buti, M. , L. Pench ad P. Sestito (1998), "European Unemployment: contending theories and institutional complexities" Policy Paper 98/1, The Robert Schuman Centre, European University Institute.

[10] Cazes, S., T. Boeri and . Bertola (1999), "Employment protection and labour market adjustment in OECD countries: Evolving institutions and variable enforcement" ILO Employment and Training Papers 48.

[11] Conde-Ruiz, J.I. and V. Galasso (1999), "Positive Arithmetic of the Welfare State", CEPR Discussion Paper \# 2202.

[12] Conde-Ruiz J.I. and V. Galasso (2003) "Early Retirement" Review of Economic Dynamics 6: 12-36.

[13] Garibaldi, P. (1997), "Job flow dynamics and firing restrictions", European Economic Review 42: 245-275. 
[14] Krueger, A. and Meyer, B. (2002) "Labour Supply Effects of Social Insurance", NBER Working Paper, n.9014.

[15] Ichino, A., M. Polo, and E. Rettore (2001), "Are Judges Biased by labour Market Conditions?" IGIER working paper.

[16] Lazear, E. (1990), "Job security provisions and employment", Quarterly Journal of Economics 105: 699-726.

[17] Mortensen, D. and Pissarides, C. (2001) Unemployment Responses to 'Skill-Biased' Shocks: The Role of Labour Market Policy, Economic Journal, 109 (242-265).

[18] OECD (1994), "labour Adjustments and Active labour Market Policies", Chapter 6 of The OECD Jobs Studies, II: Evidence and Explanations, Paris: OECD.

[19] OECD (1999) Employment Outlook, OECD, Paris.

[20] Persson, T. and G. Tabellini (2000) Political Economics. Explaining Economic Policy. The MIT Press, Cambridge, Massachusetts, London, England.

[21] Pissarides C. (2000), "Equilibrium Unemployment Theory" Cambridge: MIT Press.

[22] Pissarides, C. (2001) Employment Protection, Labour Economics, 8, 131-59.

[23] Saint-Paul, G. (1996), "Exploring the political economy of labour market institutions" Economic Policy 23: 265-315.

[24] Saint-Paul, G. (1999), "The Political Economy of Employment Protection", CEPR Discussion Paper, No. 2109

[25] Saint-Paul, G. (1999b), " Assessing the Political viability of labour Market Reform: the case of Employment Protection", CEPR Discussion Paper, No. 2136

[26] Saint-Paul, G. (2000), "The Political Economy of labour Market Institutions" $O x$ ford University Press.

[27] Wright, R (1996), "The Redistributive roles of unemployment insurance and the dynamics of voting", Journal of Public Economics 31: 377-399. 


\section{A. Appendix}

Proof of Proposition 4.1: First, we need to establish the ordering of the votes over $s$ for a given $\tau$. While high-skilled agents' preferences are single-peaked, since $\left(\partial V_{j}^{h}(s, \tau) / \partial s\right)<0 \forall j, \tau$, low-skilled agents' preferences may turn out not to be singlepeaked. Fortunately, it is easy to show that the latter display single-crossing properties. In particular, for $s^{\prime}>s$, if $V_{I}^{l}\left(s^{\prime}, \tau\right)>V_{I}^{l}(s, \tau)$, then $V_{O}^{l}\left(s^{\prime}, \tau\right)>V_{O}^{l}(s, \tau)$. We can thus order the votes over $\mathrm{s}$ as follows:

$$
s_{I}^{l}(\tau) \geq \hat{s}^{l} \geq s_{O}^{l}(\tau) \geq s_{I}^{h}=s_{O}^{h}=0 \quad \forall \tau .
$$

To prove the first part of the proposition, notice that, for a given level of EPL, $s$, the low-skill insiders are a majority if and only if $u^{l}(s)<1-\rho^{h} / \rho^{l}$. Therefore, they are a majority if this condition holds for the degree of EPL that they would choose, $s^{m}(\tau)=s_{I}^{l}(\tau)$, that is if $u^{l}\left(s_{I}^{l}\right) \leq \frac{1}{2}\left(1-\frac{\rho^{h}}{\rho^{l}}\right)$. To see that $s_{I}^{l}(\tau) \in\left(\widehat{s}^{l}, \widetilde{s}_{I}\right)$, recall that $s_{I}^{l}(\tau)$ equates the following first order condition to zero:

$$
\underbrace{\beta\left(H_{1}^{l} F^{l}-F_{1}^{l} H^{l}\right) \Delta v^{l}}_{A}-\underbrace{(1-\beta) F_{1}^{l} \Delta v^{l}}_{B}+\underbrace{\frac{F^{l}}{b^{l}}\left(1-\beta+\beta\left(F^{l}+H^{l}\right)\right) \frac{\partial b^{l}}{\partial s}}_{C} .
$$

If we evaluate this FOC in $\widehat{s}^{l}$, the first and the third terms, i.e., $A$ and $C$, are equal to zero, while the second term, and thus the entire FOC, is positive, since $F_{1}^{l}<0$. Therefore, $s_{I}^{l}(\tau)>\hat{s}^{l}$. On the other hand, if we evaluate this FOC in $\widetilde{s}_{I}$, the first two terms, i.e., $A$ and $B$, are equal to zero, since $\beta\left(H_{1}^{l} F^{l}-F_{1}^{l} H^{l}\right)-(1-\beta) F_{1}^{l}=0$ for $s=\widetilde{s}_{I}$. The third term, and thus the entire FOC, is negative, since $\left(\partial b^{l} / \partial s\right)<0$ for $s=\widetilde{s}_{I}$. To prove the second part, suppose that the low-skill insiders are not a majority for $s=s_{O}^{l}$, that is $u^{l}\left(s_{O}^{l}\right)>\frac{1}{2}\left(1-\frac{\rho^{h}}{\rho^{l}}\right)$. Because of the ordering at eq. A.1, and since $\rho^{l}>\rho^{h}$, the median vote is $s^{m}(\tau)=s_{O}^{l}(\tau)$. To see that $s_{O}^{l}(\tau) \in\left(\widetilde{s}_{O}, \widehat{s}^{l}\right)$, recall that $s_{O}^{l}(\tau)$ equates the following first order condition to zero:

$$
\begin{aligned}
\underbrace{\beta^{2}\left(H_{1}^{l} F^{l}-F_{1}^{l} H^{l}\right) \Delta v^{l}}_{A} & +\underbrace{\beta(1-\beta) H_{1}^{l} \Delta v^{l}}_{B}+ \\
& +\underbrace{\frac{\left(1-\beta+\beta F^{l}\right)}{b^{l}}\left(1-\beta+\beta\left(F^{l}+H^{l}\right)\right) \frac{\partial b^{l}}{\partial s}}_{C}
\end{aligned}
$$

If we evaluate this FOC in $\widehat{s}^{\text {}}$, the first and the third terms, i.e., $A$ and $C$, are equal to zero, while the second term, and thus the entire FOC, is negative, since $H_{1}^{l}<0$. 
Therefore, $s_{O}^{l}(\tau)<\widehat{s}^{l}$. On the other hand, if we evaluate this FOC in $\widetilde{s}_{O}$, the first two terms, i.e., $A$ and $B$, are equal to zero, since $\beta\left(H_{1}^{l} F^{l}-F_{1}^{l} H^{l}\right)-(1-\beta) H_{1}^{l}=0$ for $s=\widetilde{s}_{O}$. The third term, and thus the entire FOC, is positive, since $\left(\partial b^{l} / \partial s\right)>0$ for $s=\widetilde{s}_{O}$. q.e.d.

Lemma A.1. $s_{I}^{l}(\tau)$ is decreasing in $\tau$, while $s_{O}^{l}(\tau)$ is increasing in $\tau$.

Proof of Lemma A.1: To prove that $s_{I}^{l}(\tau)$ is decreasing in $\tau$, we apply the implicit function theorem to the FOC at eq.A.2. Since $S O C\left(s_{I}^{l}\right)<0$, we have that the sign of $d s_{I}^{l}(\tau) / d \tau$ is equal to the sign of $d F O C\left(s_{I}^{l}(\tau)\right) / d \tau$. Notice that

$$
\frac{d F O C\left(s_{I}^{l}(\tau)\right)}{d \tau}=\frac{(1-\beta) F_{1}^{l}+\beta\left(F_{1}^{l} H^{l}-H_{1}^{l} F^{l}\right)}{\tau(1-\tau)}<0 \text { for } s=s_{I}^{l}(\tau) .
$$

Thus, $s_{I}^{l}(\tau)$ is decreasing in $\tau, d s_{I}^{l} / d \tau<0$. We use the same strategy to show that $s_{O}^{l}(\tau)$ is increasing in $\tau$. The sign of $d s_{O}^{l}(\tau) / d \tau$ is equal to the sign of $d F O C\left(s_{O}^{l}(\tau)\right) / d \tau$, where

$$
\frac{d F O C\left(s_{O}^{l}(\tau)\right)}{d \tau}=\frac{(1-\beta) H_{1}^{l}-\beta\left(F_{1}^{l} H^{l}-H_{1}^{l} F^{l}\right)}{\tau(1-\tau)}>0 \text { for } s=s_{O}^{l}(\tau) .
$$

Thus, $s_{O}^{l}(\tau)$ is increasing in $\tau, d s_{O}^{l} / d \tau>0$. q.e.d.

Proof of Proposition 4.2: Recall that $\tau_{O}^{l} \geq \tau_{I}^{l} \geq \tau_{I}^{h}$. Thus, we may have that either i) $\tau_{O}^{l} \geq \tau_{O}^{h} \geq \tau_{I}^{l} \geq \tau_{I}^{h}$, in which case $\tau_{I}^{l}$ is the median over the distribution of the preferred tax rates only if the outsiders are less than half population, $u<1 / 2$; or ii) $\tau_{O}^{l} \geq \tau_{I}^{l} \geq \tau_{O}^{h} \geq \tau_{I}^{h}$, in which case $\tau_{I}^{l}$ is the median over the distribution of the preferred tax rates if the low skill outsiders are not a majority of the population, which is implied by $u<1 / 2$, since $\rho^{l} u^{l} \leq u$. q.e.d.

Lemma A.2. $\tau_{I}^{l}(s)$ is first decreasing and then increasing in $s$ with a minimum in $\widetilde{s}_{I}$.

Proof of Lemma A.2: Recall that $\tau_{I}^{l}(s)=\theta_{I}^{l}(s)$, and thus $\widetilde{s}_{I}=\arg \min \tau_{I}^{l}(s)$. By deriving the numerator of $d \theta_{I}^{l}(s) / d s$ w.r.t. $s$, it is easy to see that - under the assumptions on $F(s)$ and $H(s)$ - the function $\theta_{I}^{l}(s)=\tau_{I}^{l}(s)$ is first decreasing and then increasing in $s$, albeit not necessarily convex for $s<\widetilde{s}_{I}$. q.e.d.

Proof of Proposition 4.3: (I) For $u^{l}\left(s_{I}^{l}\right) \leq \frac{1}{2}\left(1-\frac{\rho^{h}}{\rho^{l}}\right)$, a low-skill insider is the median voter in both dimensions. Her reaction functions are $\tau_{I}^{l}(s)$ and $s_{I}^{l}(\tau)$. To need to show that these reaction functions cross - at least - once for $s^{*} \in\left(\hat{s}^{l}, \widetilde{s}_{I}\right)$ and $\tau^{*}>0$. Recall that, by lemma A.2, $\tau_{I}^{l}(s)$ is decreasing in $s$ for $s \in\left(0, \widetilde{s}_{I}\right)$. By lemma A.1, 
$s_{I}^{l}(\tau) \in\left(\widehat{s}^{l}, \widetilde{s}_{I}\right)$ is decreasing in $\tau$, however, if the preferences of the low-skill insiders are not single-peaked, $s_{I}^{l}(\tau)$ may not be continuous. Let us first consider a continuous function. By using eq. A.2, and the reasoning in Prop. 4.1, it is easy to show that $s_{I}^{l}(\tau)=\widehat{s}^{l}$ - its lower bound, see figure $1-$ for $\tau=u^{l}$. Since $\tau_{I}^{l}\left(\widehat{s}^{l}\right)=\theta_{I}^{l}\left(\widehat{s}^{l}\right)<u^{l}$, the reaction function $s_{I}^{l}(\tau)$ is above the reaction function $\tau_{I}^{l}(s)$ for $s=\widehat{s}^{l}$. To show that the two reaction functions cross, we need to establish that for $s$ close to $\widetilde{s}_{I}$ the reaction function $s_{I}^{l}(\tau)$ is below the reaction function $\tau_{I}^{l}(s)$. To see this consider the FOC at eq.A.2, which implicitly defines $s_{I}^{l}(\tau)$. Notice that as $\tau \rightarrow 0, \Delta v^{l} \rightarrow+\infty$, and the first two terms of eq.A.2 tend to $+\infty$, since $s_{I}^{l}(\tau)<\widetilde{s}_{I}$, while the third term is negative, since $s_{I}^{l}(\tau)>\widehat{s}^{l}$. Thus, according to the low skill insider optimization, for $\tau \rightarrow 0, s_{I}^{l}(\tau) \rightarrow \widetilde{s}_{I}$. Finally, notice that for $s=\widetilde{s}_{I}, \tau_{I}^{l}\left(\widetilde{s}_{I}\right)=\theta_{I}^{l}\left(\widetilde{s}_{I}\right)>0$, and the reaction function $s_{I}^{l}(\tau)$ is below the reaction function $\tau_{I}^{l}(s)$. To summarize, if the function $s_{I}^{l}(\tau)$ is continuous, it crosses $\tau_{I}^{l}(s)$ at least once for $s^{*} \in\left(\widehat{s}^{l}, \widetilde{s}_{I}\right)$ and $\tau^{*}>0$. If the function is not continuous, a (Structure Induced) equilibrium may fail to exist, since the crossing may not occur. (II) For $u^{l}\left(s_{O}^{l}\right)>\frac{1}{2}\left(1-\frac{\rho^{h}}{\rho^{l}}\right)$, the reaction function $\tau_{I}^{l}(s)$ does not change, while the median voter over $s$ becomes a low-skill outsiders, with reaction function $s_{O}^{l}(\tau)$. To need to show that these reaction functions cross - at least - once for $s^{* *} \in\left(\widetilde{s}_{O}, \widehat{s}^{l}\right)$ and $\tau^{* *}>0$. Recall that, by lemma A.1, $s_{O}^{l}(\tau) \in\left(\widetilde{s}_{O}, \widehat{s}^{l}\right)$ is increasing in $\tau$, however, if the preferences of the low-skill outsiders are not singlepeaked, $s_{O}^{l}(\tau)$ may not be continuous. Let us first consider a continuous function. By using eq. A.3, and the reasoning in Prop. 4.1, it is easy to show that $s_{O}^{l}(\tau)=\widehat{s}^{l}-$ its upper bound, see figure $1-$ for $\tau=u^{l}$. Since $\tau_{I}^{l}\left(\widehat{s}^{l}\right)=\theta_{I}^{l}\left(\widehat{s}^{l}\right)<u^{l}$, the reaction function $s_{O}^{l}(\tau)$ is above the reaction function $\tau_{I}^{l}(s)$ for $s=\widehat{s}^{l}$. To show that the two reaction functions cross, we need to establish that for $s$ close to $\widetilde{s}_{O}<\widehat{s}^{l}$ the reaction function $s_{O}^{l}(\tau)$ is below the reaction function $\tau_{I}^{l}(s)$. To see this consider the FOC at eq.A.3, which implicitly defines $s_{O}^{l}(\tau)$. Recall that as $\tau \rightarrow 0, \Delta v^{l} \rightarrow+\infty$. This implies that the first two terms of eq.A.3 tend to $-\infty$, since $s_{O}^{l}(\tau)>\widetilde{s}_{O}$, while the third term is positive, since $s_{O}^{l}(\tau)<\widehat{s}^{l}$. Thus, according to the low skill outsider optimization, for $\tau \rightarrow 0, s_{O}^{l}(\tau) \rightarrow \widetilde{s}_{O}$. Finally, notice that for $s=\widetilde{s}_{O}, \tau_{I}^{l}\left(\widetilde{s}_{O}\right)=\theta_{I}^{l}\left(\widetilde{s}_{O}\right)>0$, and thus reaction function $s_{O}^{l}(\tau)$ is below the reaction function $\tau_{I}^{l}(s)$. To summarize, if the function $s_{O}^{l}(\tau)$ is continuous, it crosses $\tau_{O}^{l}(s)$ at least once for $s^{* *} \in\left(\widetilde{s}_{O}, \widehat{s}^{l}\right)$ and $\tau^{* *}>0$. If the function is not continuous, a (Structure Induced) equilibrium may fail to exist, since the crossing may not occur. (III) If an equilibrium exists in case (I) and (II), then $\widetilde{s}_{O}<s^{* *}<\widehat{s}^{l}<s^{*}<\widetilde{s}_{I}$ Moreover, since both $\left(\tau^{*}, s^{*}\right)$ and $\left(\tau^{* *}, s^{* *}\right)$ occur on the decreasing portion of $\tau_{I}^{l}(s)$, then $\tau^{*}=\tau_{I}^{l}\left(s^{*}\right)<\tau^{* *}=\tau_{I}^{l}\left(s^{* *}\right)$, since $s^{* *}<s^{*}$. q.e.d.

Proof of Proposition 4.4: For $u^{l}\left(s_{I}^{l}\right) \leq \frac{1}{2}\left(1-\frac{\rho^{h}}{\rho^{l}}\right)$, an equilibrium outcome $\left(\tau^{*}, s^{*}\right)$ is represented by the point in which the two reaction functions $\tau^{m}(s)$ and $s^{m}(\tau)$ cross. Suppose that, for a given $\beta$, there exists a unique crossing, and thus a 
unique equilibrium outcome $\left(\tau^{*}, s^{*}\right)$. A decrease in $\beta$ shifts the reaction function $\tau^{m}(s)$ downward. In fact, $\partial \tau^{m}(s) / \partial \beta=F^{l} /\left(1-\beta+\beta F^{l}+\beta H^{l}\right)^{2}>0$. The other reaction function, $s^{m}(\tau)$, is implicitly defined at A.2. To calculate the effect of a change in $\beta$ on $s^{m}(\tau)$, we need to total differentiate this equation. Thus, $\frac{d s}{d \beta}=-\frac{d F O C(s) / d \beta}{\operatorname{soc}(s)}$, and $\operatorname{sign}\left(\frac{d s}{d \beta}\right)=\operatorname{sign}\left(\frac{d F O C(s)}{d \beta}\right)$, since $\operatorname{soc}\left(s^{m}\right)<0$. By differentiating eq.A.2 w.r.t. $\beta$, we obtain that $\frac{d F O C(s)}{d \beta}=\frac{F^{l}\left(F_{1}^{l}+H_{1}^{l}\right) \Delta v^{l}}{\left(1-\beta+\beta\left(F^{l}+H^{l}\right)\right)^{2}} \leq 0$. Thus, $d s / d \beta \leq 0$, a decrease in $\beta$ moves the reaction function $s^{m}(\tau)$ upward. Recall that the reaction function $s^{m}(\tau)$ crosses $\tau^{m}(s)$ on its decreasing portion. Thus, by putting together the downward shift in $\tau^{m}(s)$ and the upward movement in $s^{m}(\tau)$, it is easy to see that a decrease in $\beta$ leads to a new equilibrium outcome $\left(\tau^{* \prime}, s^{* \prime}\right)$, with $\tau^{* \prime}<\tau^{*}$ and $s^{* \prime}>s^{*}$. q.e.d.

\section{B. Appendix Alternative Specifications}

\section{B.0.1. Risk Aversion and Capital Markets}

Here, we extend our baseline model, in which the utility function is logarithmic $(\gamma=1)$, to a CES instant utility function: $v(c)=c^{1-\gamma} /(1-\gamma)$. It is easy to show that an increase in the degree of risk aversion does not change the order of votes along any of the two dimensions. It does however shift the reaction functions. More risk averse agents prefer more insurance against unemployment risk: for any given degree of EPL; a low-skill insider will vote for a higher tax rate, $\tau$ for any $s$. Geometrically, the reaction function $\tau_{I}^{l}(s)$ shifts upwards, as depicted in Figure B.1. An increase in the degree of risk aversion has opposite effects on the voting behavior of low-skill insiders and lowskill outsiders, and thus on the reaction functions, $s_{I}^{l}(\tau)$ and $s_{O}^{l}(\tau)$. In particular, for a given tax rate, $\tau$, it increases the most preferred degree of EPL of a low-skill outsider thus moving $s_{O}^{l}(\tau)$ to the right - whilst it decreases the voted EPL of a low-skill insider - thus shifting $s_{I}^{l}(\tau)$ to the left. The intuition is as follows. More risk averse individuals attach greater value to consumption when unemployed. If the median voter is a lowskill insider, a decrease in the degree of EPL (as compared with the baseline model) increases UBs, by reducing the average unemployment rate (recall that $s_{I}^{l}(\tau)>\widehat{s}^{l}$ ), but it increases her probability of becoming unemployed (recall that $s_{I}^{l}(\tau)<\widetilde{s}_{I}$ ), as shown in figure 3.3. The next Proposition shows that the former effect dominates and thus the reaction function $s_{I}^{l}(\tau)$ shifts to the left, as in figure B.1. If the median voter is a low-skill outsider, on the other hand, unemployment benefits increase, through a reduction in the average unemployment rate, if the the degree of EPL increases (recall that $s_{O}^{l}(\tau)<\hat{s}^{l}$ ). This also increases the low-skill outsider's probability of remaining unemployed (recall that $s_{O}^{l}(\tau)>\widetilde{s}_{O}$ ). However, since the former effect dominates - see next Proposition - the reaction function $s_{O}^{l}(\tau)$ moves to the right, as in figure B.1. 


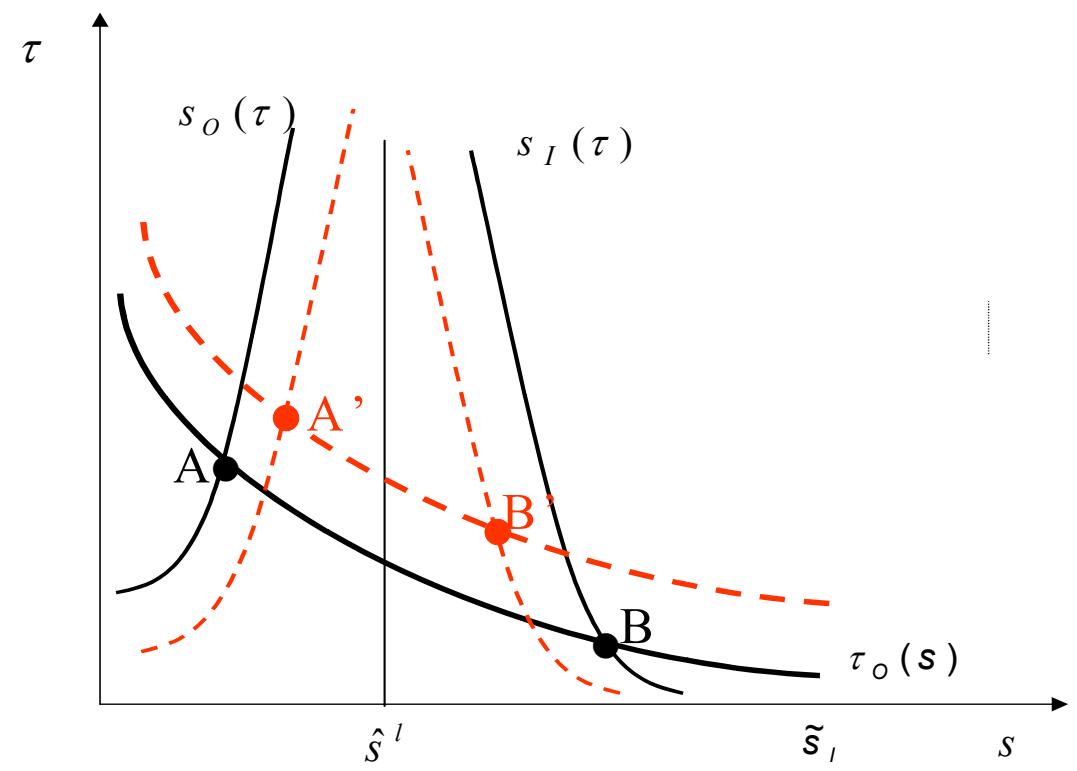

Figure B.1: Increasing risk-aversion.

Proposition B.1. i) $s_{I}^{l}(\tau)$ is non-decreasing in the coefficient of risk aversion, while $s_{O}^{l}(\tau)$ is non-increasing in the coefficient of risk aversion; ii) $\tau_{I}^{l}(s)$ is non-decreasing in the coefficient of risk aversion.

\section{Proof.}

i) For a given UB, the most preferred level of EPL of a low skill with a current status $j=I, O$, (i.e. $\left.s_{j}^{l}(\tau)\right)$ is implicitly defined by the following first order condition:

$$
\frac{\partial V_{j}^{l}(s, \tau)}{\partial s}=-\frac{\partial \theta_{j}^{l}}{\partial s} \Delta v^{l}+\theta_{j}^{l} \frac{\partial v\left(b^{l}\right)}{\partial b^{l}} \frac{\partial b^{l}}{\partial s}=0
$$

where $\Delta v^{l}=\frac{\left.\left(w^{l}(1-\tau)\right)^{1-\gamma}-\left(b^{l}\right)^{1-\gamma}\right)}{1-\gamma}$ and $\frac{\partial v\left(b^{l}\right)}{\partial b^{l}} \frac{\partial b^{l}}{\partial s}=\left(w^{l} \tau\right)^{1-\gamma} \frac{H^{l} F_{1}^{l}-H_{1}^{l} F^{l}}{\left(F^{l}\right)^{2-\gamma}\left(H^{l}\right)^{\gamma}}$. To calculate the effect of a change of the coefficient of risk aversion $\gamma$ on $s_{j}^{l}(\tau)$ we need to total differentiate this equation $d s_{j}^{l}(\tau) / d \gamma=-\frac{d F O C\left(s_{j}^{l}\right) / d \gamma}{S O C\left(s_{j}^{l}\right)}$; and the $\operatorname{sign}\left(d s_{j}^{l}(\tau) / d \gamma\right)=\operatorname{sign}$ $\left(d F O C\left(s_{j}^{l}\right) / d \gamma\right)$, since $S O C\left(s_{j}^{l}\right) \leq 0$. By differentiating $F O C\left(s_{j}^{l}\right) / d \gamma$ w.r.t. $\gamma$, we obtain that: 


$$
\begin{aligned}
& \frac{d F O C\left(s_{j}^{l}\right)}{d \gamma}=\frac{\partial \theta_{j}^{l}}{\partial s} \frac{\left(w^{l}(1-\tau)\right)^{1-\gamma} \ln \left(w^{l}(1-\tau)\right)-\left(b^{l}\right)^{1-\gamma} \ln \left(b^{l}\right)}{1-\gamma}+ \\
& -\frac{\partial \theta_{j}^{l}}{\partial s} \frac{\left(w^{l}(1-\tau)\right)^{1-\gamma}-\left(b^{l}\right)^{1-\gamma}}{(1-\gamma)^{2}}+\theta_{j}^{l} \frac{H^{l} F_{1}^{l}-H_{1}^{l} F^{l}}{\left(F^{l}\right)^{2-\gamma}\left(H^{l}\right)^{\gamma}}\left(w^{l} \tau\right)^{1-\gamma}\left[\ln \left(w^{l} \tau\right)-\ln F^{l}+\ln H^{l}\right]
\end{aligned}
$$

using eq B.1, we have that

$$
\frac{d F O C\left(s_{j}^{l}\right)}{d \gamma}=-\frac{\partial \theta_{j}^{l}}{\partial s}\left[\frac{\left(w^{l}(1-\tau)\right)^{1-\gamma}-\left(b^{l}\right)^{1-\gamma}}{(1-\gamma)^{2}}-\frac{\left(w^{l}(1-\tau)\right)^{1-\gamma} \ln \left(\frac{w^{l}(1-\tau)}{b^{l}}\right)}{1-\gamma}\right]
$$

Using the first order condition for the outsider low skill, we know that $\partial \theta_{O}^{l} / \partial s \geq 0$ for $s=s_{O}^{l}(\tau)$. Simple algebra shows that the term in brackets in eq. B.2 is non-negative, and hence $d s_{O}^{l}(\tau, \gamma) / d \gamma \geq 0$.

To complete the proof of the part i) notice that by the same reasoning since $\partial \theta_{I}^{l} / \partial s \leq$ 0 for $s=s_{I}^{l}(\tau)$ we have that $d s_{I}^{l}(\tau, \gamma) / d \gamma \leq 0$.

ii) For a given EPL, the most preferred level of UB of a low skill insider ,(i.e. $\tau_{I}^{l}(s)$ ) is defined implicitly by the following first order condition:

$$
\frac{\partial V_{I}^{l}(s, \tau)}{\partial \tau}=-\left(1-\theta_{I}^{l}\right)\left(w^{l}(1-\tau)\right)^{-\gamma} w^{l}+\theta_{I}^{l}\left(b^{l}\right)^{-\gamma} \frac{\partial b^{l}}{\partial \tau}=0
$$

from which we have

$$
\tau_{I}^{l}(s)=\frac{\beta^{\frac{1}{\gamma}} F^{l}\left(H^{l}\right)^{\frac{1-\gamma}{\gamma}}}{(1-\beta+\beta H)^{\frac{1}{\gamma}}+\beta^{\frac{1}{\gamma}} F^{l}\left(H^{l}\right)^{\frac{1-\gamma}{\gamma}}}
$$

by deriving $\tau_{I}^{l}(s)$ with respect to $\gamma$ we have that $d \tau_{I}^{l}(s) / d \gamma \geq 0$. q.e.d.

Figure B.1 suggests that - for any degree of risk aversion, $\gamma$ - a trade off between EPL and UB still exists. However, the degree of risk aversion does affect the equilibrium. If the median voter on both dimensions is a low-skill insider, more risk aversion induces a substitution of EPL with UB (a shift from equilibrium B to B' in Figure B.1). If the median voter over $s$ is a low-skill outsider, i.e., when there are more high-skill agents in the economy, an increase in the degree of EPL increases the EPL and has an ambiguous impact on the tax rate.

\section{B.0.2. Unemployment Benefit and (Low-skill) Outflow Rate}

In this section, we return to the logarithmic utility function, and analyze what happens when the outflow rate of the low-skill agents depends on the UBs. In particular, we assume that the low-skill unemployment outflow rate is negatively related 
to the tax rate, $\tau$, which finances UBs: $H_{2}^{l}(s, \tau)<0$. This extension introduces substantial modifications to the structure of the model. In particular, the degree of EPL which minimizes the unemployment rate among the low-skill agents will now depend negatively on the tax rate, $\widehat{s}^{l}(\tau)$. Analogously, the levels of EPL which minimize the time spent unemployed respectively by a low-skill insider and outsider $\widetilde{s}_{I}=\arg \min \theta_{I}^{l}(s)$ and $\widetilde{s}_{O}=\arg \min \theta_{O}^{l}(s)$ - will now be negatively affected by the tax rate: $\widetilde{s}_{O}(\tau)<\widehat{s}^{l}(\tau)<\widetilde{s}_{I}(\tau)$.

Proposition B.2. In a model with $H_{2}^{l}(s, \tau)<0, \widehat{s}^{l}(\tau), \widetilde{s}_{I}(\tau)$ and $\widetilde{s}_{O}(\tau)$ are nonincreasing in $\tau$, and $\widetilde{s}_{O}(\tau)<\widehat{s}^{l}(\tau)<\widetilde{s}_{I}(\tau) \forall \tau$.

\section{Proof:}

In this setting $u^{l}(s, \tau)=F^{l}(s) /\left(F^{l}(s)+H^{l}(s, \tau)\right)$, and the level of EPL which minimizes the unemployment of low skill workers $\left(\widehat{s}^{l}(\tau)\right)$ will depend on the level of UB. It is easy to see that $d \widehat{s}^{l}(\tau) / d \tau \leq 0$. Analogously, the proportion of time that a low skill type with current status $j=I, O$ will spend unemployment during her lifetime also depends on the level of UB. In particular, $\theta_{O}^{l}(s, \tau)=\left(1-\beta+\beta F^{l}(s)\right) /\left(1-\beta+\beta\left(F^{l}(s)+H^{l}(s, \tau)\right)\right)$ and $\theta_{I}^{l}(s, \tau)=\beta F^{l}(s) /\left(1-\beta+\beta\left(F^{l}(s)+H^{l}(s, \tau)\right)\right)$. Therefore the level of EPL which minimizes $\theta_{O}^{l}(s, \tau)$ an $\theta_{I}^{l}(s, \tau)$ also depends on UB. It is easy to see that $d \widetilde{s}_{I}^{l}(\tau) / d \tau \leq 0$ and $d \widetilde{s}_{O}(\tau) / d \tau \leq 0$. Finally, the inequality $\widetilde{s}_{O}(\tau)<\widehat{s}^{l}(\tau)<\widetilde{s}_{I}(\tau) \forall \tau$ follows easily from the above equations. q.e.d.

How about the agents' voting behavior under this new environment? Consider the votes over the degree of EPL. If the median voter is a low-skill insider, then there is no difference with respect to the baseline. The reaction function $s_{I}^{l}(\tau)$ is negatively sloped and $\widehat{s}^{l}(\tau)<s_{I}^{l}(\tau)<\widetilde{s}_{I}(\tau)$. When the median voter is a low-skill outsider, we cannot determine exactly how the reaction function $s_{O}^{l}(\tau)$ will depend on the tax rate, $\tau$, i.e., the sign of the derivative of $s_{O}^{l}(\tau)$ w.r.t. $\tau$. However, we know that $\widetilde{s}_{O}(\tau)<s_{O}^{l}(\tau)<$ $\hat{s}^{l}(\tau)$. When voting on the tax rate, we clearly have that $\tau_{I}^{l}<\theta_{I}^{l}$, where $\theta_{I}^{l}$ was the solution in the baseline case, due to the additional negative effect of the tax rate on the outflow rate. Moreover, we can show that $\tau_{I}^{l}(s)$ is decreasing in the degree of EPL, as long as $s<\widetilde{s}_{I}(\tau)$. Figure B.2 summarizes all the reaction functions and highlights that, as in the baseline case, with this specification a trade off between the degree of EPL and the generosity of unemployment benefits still arises, depending on the skill composition of the economy. The next proposition formalizes the previous statements.

Proposition B.3. In a model with $H_{2}^{l}(s, \tau)<0$ :

(I) If $\left[1-u^{l}\left(s_{I}^{l}, \tau\right)\right] \rho^{l} \geq \frac{1}{2}$, there typically exists a structure-induced equilibrium (SIE) of the voting game $\left(\tau^{*}, s^{*}\right)$, such that $\tau^{*}=\tau_{I}^{l}\left(s_{I}^{l}\right)$ and $s^{*}=s_{I}^{l}\left(\tau_{I}^{l}\right) \in\left(\widehat{s}^{l}, \widetilde{s}_{I}\right)$; 


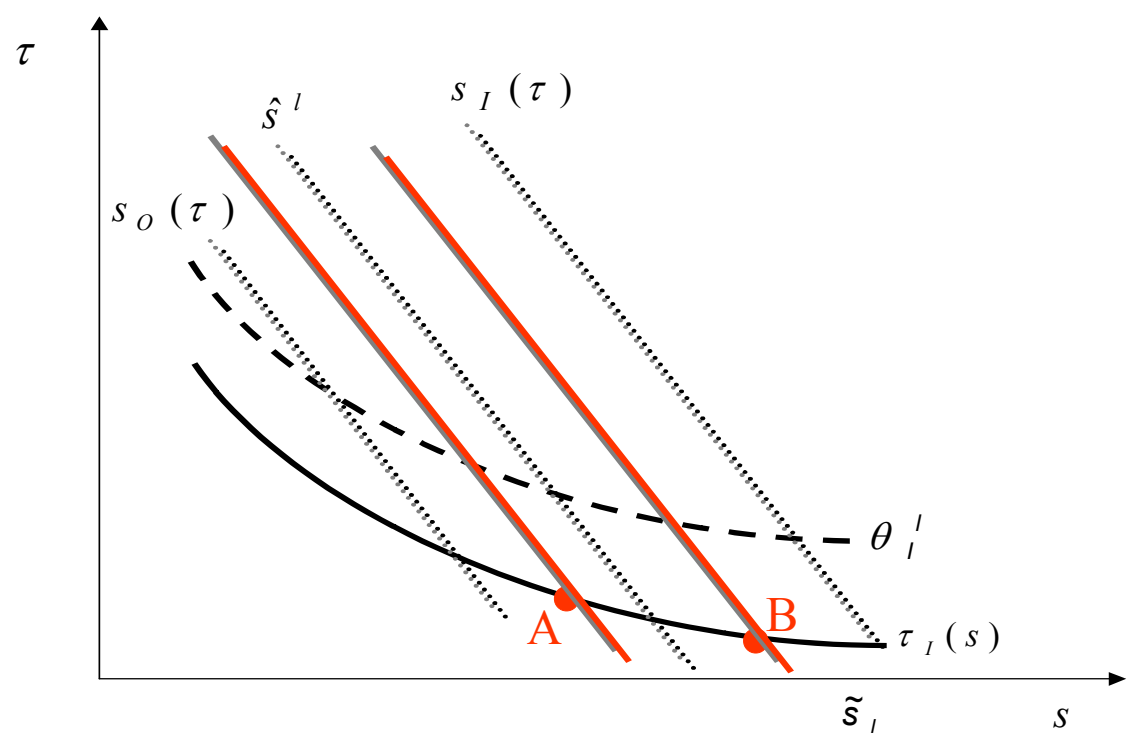

Figure B.2: Unemployment benefits and the outflow rate of low-skill types

(II) If $\left[1-u^{l}\left(s_{O}^{l}, \tau\right)\right] \rho^{l}<\frac{1}{2}$, there typically exists a structure-induced equilibrium (SIE) of the voting game $\left(\tau^{* *}, s^{* *}\right)$, such that $\tau^{* *}=\tau_{I}^{l}\left(s_{O}^{l}\right)$ and $s^{* *}=s_{O}^{l}\left(\tau_{I}^{l}\right) \in$ $\left(\widetilde{s}_{O}, \widehat{s}^{l}\right)$.

(III) If $\left(\tau^{*}, s^{*}\right)$ and $\left(\tau^{* *}, s^{* *}\right)$ exist, then $s^{* *}<s^{*}$ and $\tau^{* *}>\tau^{*}$.

\section{Proof:}

First, we establish some results that hold in this new environment, then we follow the proof of proposition 4.1 .

i) Voting behavior over EPL. As in Proposition 4.1, it is easy to see that ideal point for a low skill insider and outsider are respectively:

$$
\begin{aligned}
& s_{O}^{l}(\tau) \in\left(\widehat{s}_{O}^{l}(\tau), \widehat{s}^{l}(\tau)\right) \\
& s_{I}^{l}(\tau) \in\left(\widehat{s}^{l}(\tau), \widehat{s}_{I}^{l}(\tau)\right)
\end{aligned}
$$

ii) Voting behavior over UB. For a given EPL, the most preferred level of UB of a low skill insider, i.e., $\tau_{I}^{l}(s)$, is defined implicitly by the following first order condition:

$$
\frac{\partial V_{I}^{l}(s, \tau)}{\partial \tau}=-\frac{\left(1-\theta_{I}^{l}\right)}{(1-\tau)}-\log \left(w^{l}(1-\tau)\right) \frac{\theta_{I}^{l}}{\partial \tau}+\theta_{I}^{l}\left(b^{l}\right)^{-\gamma} \frac{\partial b^{l}}{\partial \tau}+\frac{\theta_{I}^{l}}{\partial \tau} \log \left(b^{l}\right)=0
$$


which, after some algebra, becomes :

$$
\frac{\partial V_{I}^{l}(s, \tau)}{\partial \tau}=\frac{\theta_{I}^{l}-\tau}{(1-\tau) \tau}+\theta_{I}^{l} H_{\tau}^{l}\left(\frac{1}{H^{l}}+\frac{\beta \Delta v^{l}}{\left(1-\beta+\beta\left(F^{l}+H^{l}\right)\right)}\right)=0
$$

therefore $\tau_{I}^{l}<\theta_{I}^{l}$. We now need to proof that $\tau_{I}^{l}(s)$ is decreasing in $s \in\left[0, \widetilde{s}_{I}^{l}\right]$ (i.e., that Lemma A.2 holds in this environment). To calculate the effect of a change of the EPL on $\tau_{I}^{l}$ we total differentiate the previous equation $d \tau_{I}^{l}(s) / d s=-\frac{d F O C\left(\tau_{I}^{l}\right) / d s}{\operatorname{SOC}\left(\tau_{I}^{l}\right)}$; and the $\operatorname{sign}\left(d \tau_{I}^{l}(s) / d s\right)=\operatorname{sign}\left(d F O C\left(\tau_{I}^{l}\right) / d s\right)$, since $S O C\left(\tau_{I}^{l}\right) \leq 0$. By differentiating $d F O C\left(\tau_{I}^{l}\right) / d s$ w.r.t. $s$, we obtain that:

$$
\begin{aligned}
& \frac{d F O C\left(\tau_{I}^{l}\right)}{d s}=\frac{\partial \theta_{I}^{l} / \partial s}{(1-\tau) \tau}+\partial \theta_{I}^{l} / \partial s H_{\tau}^{l}\left(\frac{1}{H^{l}}+\frac{\beta \Delta v^{l}}{\left(1-\beta+\beta\left(F^{l}+H^{l}\right)\right)}\right)+ \\
& \theta_{I}^{l} H_{\tau}^{l}\left(\frac{-H_{1}^{l}}{\left(H^{l}\right)^{2}}+\frac{\frac{\beta}{F}\left(H_{1}^{l} F^{l}-H^{l} F_{1}^{l}\right)\left(1-\beta+\beta\left(F^{l}+H^{l}\right)\right)-\beta \Delta v^{l} \beta\left(F_{1}^{l}+H_{1}^{l}\right)}{\left(1-\beta+\beta\left(F^{l}+H^{l}\right)\right)^{2}}\right)
\end{aligned}
$$

In order to proof that $\tau_{I}^{l}(s)$ is decreasing in $s \in\left[0, \widetilde{s}_{I}^{l}\right]$ it is sufficient to show that

$$
\begin{aligned}
& \left.\frac{d F O C\left(\tau_{I}^{l}\right)}{d s}\right|_{s=s_{I}^{l}}= \\
= & -H_{1}^{l} \theta_{I}^{l} \frac{H_{\tau}^{l}}{\left(H^{l}\right)^{2}}-\theta_{I}^{l} H_{\tau}^{l} \frac{(1-\beta) F_{1}^{l}}{F^{l} H^{l}\left(1-\beta+\beta\left(F^{l}+H^{l}\right)\right)}-\theta_{I}^{l} H_{\tau}^{l} \frac{\beta^{2} \Delta v^{l}\left(F_{1}^{l}+H_{1}^{l}\right)}{\left(1-\beta+\beta\left(F^{l}+H^{l}\right)\right)^{2}} \leq 0
\end{aligned}
$$

which is always true because $H_{\tau}^{l} \leq 0, H_{1}^{l} \leq 0$ and $H_{1}^{l} \leq 0$.

The remaining of the follows the proof of Proposition 4.1.q.e.d.

\section{B.0.3. Redistributive Unemployment Benefit}

We consider a redistributive unemployment benefit program, which imposes a proportional tax, $\tau$, on the labour income of all workers and awards to every unemployed agent a flat transfer, $b$, which does not depend on her previous wage, or type. As in the baseline case, the system is budget balanced and thus the total amount of transfers to the unemployed equals the total contributions. Thus, we have:

$$
b=\tau \frac{w^{l} \rho_{l}\left(1-u^{l}\right)+w^{h} \rho_{h}\left(1-u^{h}\right)}{u^{l} \rho_{l}+u^{h} \rho_{h}} .
$$

How does the existence of a redistributive unemployment benefit program affect the agents' voting behavior? Consider the voting over the degree of EPL for a given level of the tax rate, $\tau$. With respect to the baseline case, there are two differences: (i) for a 


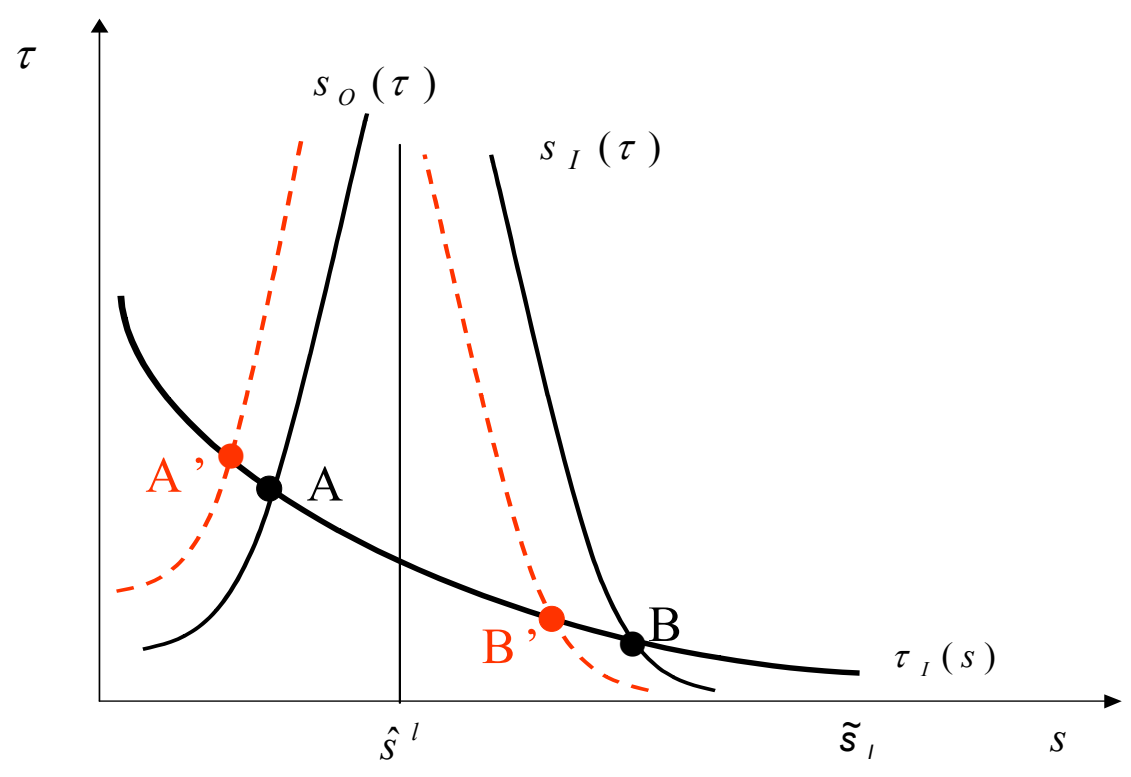

Figure B.3: Redistributive unemployment benefits.

given degree of EPL, UB and hence consumption when unemployed, increases for the low skill types - while it decreases for the high skill individuals - due to the redistribution, and (ii) the impact of the EPL on the utility of the unemployed is magnified, since an increase in the degree of EPL reduces the employment rate of the high skill agents, and hence UB. Both effects induce the low skill types to vote for a low degree of EPL - the former because being unemployed becomes less costly, and the latter due to the negative impact of the EPL on the unemployment benefit. Hence, as shown in figure B.3, both reaction functions, $s_{I}^{l}(\tau)$ (if the median voter is a low-skill insider) and $s_{O}^{l}(\tau)$ (if the median voter is a low-skill outsider) shift to the left, as low-skill agents now prefer less EPL. When voting on the tax rate financing UBs, two new effects emerge for the low skill agents with respect to the baseline case. An increase in the tax rate generates larger UBs for the low skill outsiders, due to the redistributive component of the program. This creates a substitution effect, as low skill agents are induced to vote for more UB, and an income effect, that induces low skill agents to vote for less UB. With our logarithmic utility function, the two effects cancel out, and thus the reaction function $\tau_{I}^{l}(s)$ does not move $^{18}$. Figure B.3 displays the equilibrium with the redistributive unemployment

\footnotetext{
${ }^{18}$ If we consider the CES instant utility function of the previous section, we have that for $\gamma>1$ the income effect dominates and the reaction function moves downward, whereas for $\gamma<1$, the substitutioi
} 
benefits and a logarithmic utility function: the two reaction functions $s_{I}^{l}(\tau)$ and $s_{O}^{l}(\tau)$ have shifted to the left, while $\tau_{I}^{l}(s)$ has not changed. The next proposition characterizes these equilibria.

Proposition B.4. In a model with redistributive unemployment benefits, for $s_{O}^{l}(\tau) \geq$ $s_{I}^{h}(\tau) \forall \tau$ :

(I) If $\left[1-u^{l}\left(s_{I}^{l}\right)\right] \rho^{l} \geq \frac{1}{2}$, there typically exists a structure-induced equilibrium (SIE) of the voting game $\left(\tau^{*}, s^{*}\right)$, such that $\tau^{*}=\tau_{I}^{l}\left(s_{I}^{l}\right)$ and $s^{*}=s_{I}^{l}\left(\tau_{I}^{l}\right) \in\left(\widehat{s}^{l}, \widetilde{s}_{I}\right)$;

(II) If $\left[1-u^{l}\left(s_{O}^{l}\right)\right] \rho^{l}<\frac{1}{2}$, there typically exists a structure-induced equilibrium (SIE) of the voting game $\left(\tau^{* *}, s^{* *}\right)$, such that $\tau^{* *}=\tau_{I}^{l}\left(s_{O}^{l}\right)$ and $s^{* *}=s_{O}^{l}\left(\tau_{I}^{l}\right) \in\left(\widetilde{s}_{O}, \widehat{s}^{l}\right)$.

(III) If $\left(\tau^{*}, s^{*}\right)$ and $\left(\tau^{* *}, s^{* *}\right)$ exist, then $s^{* *}<s^{*}$ and $\tau^{* *}>\tau^{*}$.

Proof: To prove this proposition we analyze how the median voter's reaction functions change with respect to the baseline case (from now our $B C$ ). The reader can easily complete the proof following the proof of Proposition 4.3.

i) Voting over EPL for a given UB. The most preferred level of EPL of a low skill with a current status $j=I, O$, (i.e. $\left.s_{j}^{l}(\tau)\right)$ is defined implicitly by the following first order condition:

$$
\frac{\partial V_{j}^{l}(s, \tau)}{\partial s}=-\frac{\partial \theta_{j}^{l}}{\partial s} \Delta v^{l}+\theta_{j}^{l} \frac{\partial v(b)}{\partial s}=g_{j}^{l}(s) \Delta v^{l}+\theta_{j}^{l} f(s)=0
$$

while the analogous first order condition in our baseline case was

$$
\frac{\partial V_{j}^{l}(s, \tau)}{\partial s}=-\frac{\partial \theta_{j}^{l}}{\partial s} \Delta v_{B C}^{l}+\theta_{j}^{l} \frac{\partial v\left(b_{B C}^{l}\right)}{\partial s}=g_{j}^{l}(s) \Delta v_{B C}^{l}+\theta_{j}^{l} f^{B C}(s)
$$

where $g_{j}^{l}(s)=-\partial \theta_{j}^{l} / \partial s ; f(s)=\partial v(b) / \partial s$ and $f^{B C}(s)=\partial v\left(b_{B S}^{l}\right) / \partial s$. Notice that there are two changes with respect the baseline case, due to the intragenerational redistribution element of the UB: i) $b_{B C}^{l}<b$, therefore we have that $\Delta v^{l}<\Delta v_{B C}^{l}$ and; ii) $\partial b / \partial s<\partial b_{B C}^{l} / \partial s$. Since $g_{j}^{l}(s)$ is equal in the two FOCs and $f(s)$ steeper and cross the axis for a low level of $s$, it is easy to see that for a given $\tau: s_{I}^{l}(\tau)<\left.s_{I}^{l}(\tau)\right|_{B C}$ and $s_{O}^{l}(\tau)<\left.s_{O}^{l}(\tau)\right|_{B C}$, but still $s_{I}^{l}(\tau)>s_{O}^{l}(\tau)$.

On the other hand, the most preferred level of EPL of a high skill with a current status $j=I, O$ could be greater or equal to zero. However, we assumed that $s_{O}^{l}(\tau) \geq$ $s_{I}^{h}(\tau)$.

i) Voting over UB for a given EPL. Because of the logarithmic utility function assumption the voting behavior over this dimension is exactly the same as in the baseline case, and therefore the median voter reaction function remains unaffected: $\tau_{I}^{l}(s)=$ $\left.\tau_{I}^{l}(s)\right|_{B C} \cdot \mathbf{q . e . d}$.

effect dominates and the reaction function moves upward. 


\section{RELACION DE DOCUMENTOS DE FEDEA}

\section{DOCUMENTOS DE TRABAJO}

2003-17: "Protecting Against Labour Market Risk: Employment Protection or Unemployment Benefits?", Tito Boeri, J. Ignacio Conde-Ruiz y Vincenzo Galasso.

2003-16: “What Social Security: Beveridgean or Bismarckian?", J. Ignacio Conde-Ruiz y Paola Profeta.

2003-15: "Forecasting the Dollar/Euro Exchange Rate: Can International Parities Help?", Simón Sosvilla-Rivero y Emma García.

2003-14: "Employment Consequences of Restrictive Permanent Contracts: Evidence from Spanish Labor Market Reforms", Adriana Kugler, Juan F. Jimeno y Virginia Hernanz.

2003-13: "The underestimated virtues of the two-sector AK model", Gabriel J. Felbermayr y Omar Licandro.

2003-12: “The Effects of Employment Protection: Learning from Variable Enforcement", Tito Boeri y Juan F. Jimeno.

2003-11: "The effect of Structural Fund spending on the Spanish regions: an assessment of the 199499 Objective 1 CSF", Angel de la Fuente.

2003-10: "Spanish Unemployment: The End of the Wild Ride?, Samuel Bentolila y Juan F. Jimeno.

2003-09: “A New Test for Chaotic Dynamics Using Lyapunov Exponents”, Fernando FernándezRodríguez, Simón Sosvilla-Rivero y Julián Andrada-Félix.

2003-08: "Endogenous Policy Leads to Inefficient Risk Sharing", Marco Celentani, J. Ignacio Conde-Ruiz y Klaus Desmet.

2003-07: "Efectos a largo plazo sobre la economía andaluza de las ayudas procedentes de los fondos estructurales: el Marco de Apoyo Comunitario 1994-1999”, Encarnación Murillo García y Simón Sosvilla-Rivero.

2003-06: "The Role of Education vis-à-vis Job Experience in Explaining the Transitions to Employment in the Spanish Youth Labour Market", Cristina Fernández.

2003-05: "The Macroeconomics of Early Retirement", J. Ignacio Conde-Ruiz y Vincenzo Galasso.

2003-04: "Positive Arithmetic of the Welfare State", J. Ignacio Conde-Ruiz y Vincenzo Galasso.

2003-03: "Early retirement", J. Ignacio Conde-Ruiz y Vincenzo Galasso.

2003-02: "Balance del sistema de pensiones y boom migratorio en España. Nuevas proyecciones del modelo MODPENS a 2050", Javier Alonso Meseguer y José A. Herce.

2003-01: "Convergence in social protection across EU countries, 1970-1999", Simón SosvillaRivero, José A. Herce y Juan-José de Lucio.

2002-26: "Temporary Employment and Segmentation in the Spanish Labour Market: an Empirical Analysis through the Study of Wage Differentials", María A. Davia y Virginia Hernanz.

2002-25: "Efectos económicos de las inversiones ferroviarias, 1991-2007", José A. Herce y Simón Sosvilla-Rivero.

2002-24: "Assessing self-assessed health data", Namkee Ahn.

2002-23: "Especialización productiva y asimetrías en las fluctuaciones económicas en las regiones europeas", Jordi Pons Novell y Daniel A. Tirado Fabregat.

2002-22: "An Eclectic Approach to Currency Crises: Drawing Lessons from the EMS Experience", Reyes Maroto, Francisco Pérez y Simón Sosvilla-Rivero.

2002-21: "Migration Willingness in Spain: Analysis of Temporal and Regional Differences", Namkee Ahn, Juan F. Jimeno y Emma García.

2002-20: “¿Es relevante el trato fiscal diferencial en el volumen de ahorro de los individuos?”, José A. Herce. 